\title{
Characterization of CO Thermochemistry in Incident Shockwaves
}

\author{
Brett A. Cruden ${ }^{1}$, Aaron M. Brandis ${ }^{1}$ \\ AMA, Inc. at NASA Ames Research Center, Moffett Field, CA, 94035 \\ Megan E. MacDonald ${ }^{2}$ \\ Jacobs Technology at NASA Ames Research Center, Moffett Field, CA, 94035
}

Incident shock waves in pure CO have been characterized in the Electric Arc Shock Tube facility at NASA Ames Research Center. Spectrally and spatially resolved emission spectra characterize radiative signatures from $\mathrm{CO}$ in the VUV and mid-infrared and atomic carbon and $\mathrm{C}_{2}$ in the visible. CO absorption of a single vibrational line is also measured with a tunable diode laser. The experimental data analyzed here are at a pressure of 0.25 Torr in the driven section and span a shock velocity range from $3.4-9.5 \mathrm{~km} / \mathrm{s}$. The emission and absorption signals are analyzed to extract temperature relaxation behind the shock which is used to derive the rate of $\mathrm{CO}$ dissociation. The emission spectra are compared to results using different kinetic parameters for $\mathrm{CO}$ dissociation and $\mathrm{C}_{2}$ dissociation and exchange. Different rates from the literature are found to match the data from 3.4-6.6 km/s and 6.6-9.5 km/s. Areas for improvement in $\mathrm{CO}$ and $\mathrm{C}_{2}$ radiation modeling are suggested on the basis of the analysis.

\section{Nomenclature}

$=$ Absorbance

$=$ Einstein coefficient, $\mathrm{s}^{-1}$, or Arrhenius prefactor, $\mathrm{cm}^{3} / \mathrm{mol}-\mathrm{s}$

$=$ speed of light, $2.998 \times 10^{8} \mathrm{~m} / \mathrm{s}$

$=$ optical pathlength, or tube diameter

$=$ energy of reaction or level, $\mathrm{J} / \mathrm{mol}-\mathrm{K}$ or $\mathrm{J} / \mathrm{K}$

$=$ degeneracy

$=$ total enthalpy, $\mathrm{J} / \mathrm{kg}$, or Planck's constant, $6.636 \times 10^{-34} \mathrm{~J}-\mathrm{s}$

$=$ molar enthalpy, $\mathrm{J} / \mathrm{mol}$

$=$ intensity

$=$ rate coefficient, $\mathrm{cm}^{3} / \mathrm{mol}-\mathrm{s}$ or Boltzmann constant, $1.381 \times 10^{-23} \mathrm{~J} / \mathrm{K}$

$=$ molecular weight, $\mathrm{kg} / \mathrm{m}^{3}$

$=$ number density, $\# / \mathrm{cm}^{3}$ or exponent in modified Arrhenius equation

$=$ pressure, $\mathrm{Pa}$

$=$ partition function

$=$ reaction rate, $\mathrm{mol} / \mathrm{m}^{3}-\mathrm{s}$

$=$ ideal gas constant, $8.314 \mathrm{~J} / \mathrm{mol}-\mathrm{K}$

$=$ temperature, $\mathrm{K}$

$=$ velocity, $\mathrm{m} / \mathrm{s}$

$=$ positional co-ordinate, $\mathrm{m}$

$=$ overpopulation factor

$=$ wavelength, $\mathrm{nm}$

$=$ lineshape function, $1 / \mathrm{nm}$

$=$ density, $\mathrm{kg} / \mathrm{m}^{3}$

$=$ species mass fraction

${ }^{1}$ Sr. Research Scientist, Aerothermodynamics Branch. Associate Fellow AIAA. Contact: brett.a.cruden@nasa.gov
${ }^{2}$ Sr. Aerospace Engineer, Thermophysics Facilities Branch, Member AIAA. 


$\begin{array}{ll}\text { Subscripts } & \\ 0 & =\text { initial } \\ 1 . .14 & =\text { reaction number, forward direction } \\ -14 . .-1 & =\text { reaction number, reverse direction } \\ \text { a } & =\text { absorbed (intensity) or activation (energy) } \\ \mathrm{e} & =\text { emitted } \\ \text { eff } & =\text { effective } \\ \text { eq } & =\text { at equilibrium } \\ i & =\text { species index } \\ 1 & =\text { lower state } \\ \text { tot } & =\text { total } \\ \mathrm{u} & =\text { upper state } \\ \mathrm{ul} & =\text { from upper to lower state }\end{array}$

\section{Introduction}

$\mathrm{T}$ he atmospheres of Mars and Venus are composed primarily of $\mathrm{CO}_{2}$ with lesser amounts of $\mathrm{N}_{2}$ and Ar. Vehicles entering these atmospheres encounter significant heating by the shock heated $\mathrm{CO}_{2}$. Heating mechanisms include radiation from excited states of $\mathrm{CO}_{2}$, shock-induced reaction products $\left(\mathrm{CO}, \mathrm{C}, \mathrm{O}, \mathrm{C}_{2}\right.$, and $\left.\mathrm{CN}\right)$ and ablation products and convection from the thermally hot gas mixture. The radiative heating scales directly with species number densities and temperatures throughout the shock layer. Convective heating scales with temperature at the boundary layer edge, which itself is a function of the extent of decomposition of $\mathrm{CO}_{2}$ and $\mathrm{CO}$ within the shock layer. Therefore, it is important to understand $\mathrm{CO}_{2}$ dissociation rates and mechanisms in order to assess entry heating. The heating is particularly sensitive to the rate of $\mathrm{CO}$ dissociation. However, previous attempts to adjust reaction rates to match $\mathrm{CO}$ emission data have required assumptions to be made about both $\mathrm{CO}$ excitation rates and $\mathrm{CO}_{2}$ dissociation rates[1]. The present work intends to decouple these assumptions by performing testing in pure CO. Additionally, spectroscopic measurement of CO vibrational transitions and tunable diode laser absorption spectroscopy (TDLAS) are performed to better inform the analysis.

Data collected in the EAST facility for the purpose of understanding Mars and Venus shock layers have been reported in previous test series [2-7]. These test series have included characterization of high-speed Mars aerocapture entry conditions[2, 3], Venus probe conditions[3], low density Mars aerocapture conditions[4], gas mixture composition variations[5], characterization of mid-infrared radiance expected at lower velocity[6], and reconstruction of the Mars Science Laboratory entry with comparison to flight heating data[7]. Analysis of the quality of predictive models for $\mathrm{CO}_{2}$ radiation based on these test series has been reported in [1, 8-10]. Radiation from $\mathrm{CO}_{2}$ shocks has also been characterized in JAXA's high-velocity shock tube [11,12] and the University of Queensland's X2 facility.[13] Characterization of $\mathrm{CO}_{2}$ shocks in EAST with TDLAS was first reported in [14]. The tests analyzed in the present work have been reported in a previous conference paper [15] which focused primarily on the TDLAS analysis for shocks in pure $\mathrm{CO}$ at 0.25 Torr with velocities spanning from 3.4-8.6 km/s. Emission data was also presented in Ref. [15] in the context of determining rotational, vibrational and electronic temperature behind the shock. A more complete analysis of the TDLAS data is presented in a companion paper to the current work [16]. The current paper includes analysis of this data set in terms of temperature relaxation and the spectral and spatial trends of the major radiating species, $\mathrm{CO}$ and $\mathrm{C}_{2}$.

\section{Experiment and Analysis}

The data discussed here was collected in the NASA Ames EAST facility, which has been described in detail in previous work [17]. A $1.2 \mathrm{MJ}, 40 \mathrm{kV}$ capacitor bank drives a $10.16 \mathrm{~cm}$ aluminum tube which is filled with the test gas at $33 \mathrm{~Pa}(0.25$ Torr). Seventeen shots ( 15 with usable test data) were obtained at this pressure with velocities ranging from $3.4-9.5 \mathrm{~km} / \mathrm{s}$. Spatially resolved radiance is imaged onto four spectrometers, producing spectrally and spatially resolved radiance data in each test. At the same time, a tunable diode laser scans over one vibrational transition at $4.36 \mu \mathrm{m}$, measuring the absorption lineshape of $\mathrm{CO}[14,15]$. One lineshape is measured in $0.5 \mu \mathrm{s}$. Emission data are collected at low resolution over four wavelength ranges: 145-195 nm, 190-340 nm, 480-890 nm and 4000-5000 nm. These ranges characterize the A-X (electronic) transition of CO, Swan bands of the $\mathrm{C}_{2}$ radical and $\mathrm{CO}$ vibrational $(\Delta v=1)$ transitions. The low wavelength region of the $\mathrm{A}-\mathrm{X}$ band is fit to obtain the limiting Planck function that describes the electronic temperature of $\mathrm{CO}$ [3]. The $\mathrm{C}_{2}$ Swan band is analyzed to obtain the rovibrational temperature [3]. 
Equilibrium conditions of pure $\mathrm{CO}$ shocks were evaluated using the Chemical Equilibrium with Application (CEA) program [18] and are plotted in Figure 1. The temperatures, mole fraction and total number density are given as a function of velocity. Equilibrium temperatures span 4000-8000K. The major decomposition products of CO are atomic $\mathrm{C}$ and $\mathrm{O}$, in stoichiometric ratio. Carbon is the primary ionized species, forming at $\sim 100 \mathrm{ppm}$ at $4 \mathrm{~km} / \mathrm{s}$ and increasing up to $\sim 1 \%$ at $10 \mathrm{~km} / \mathrm{s}$. Lesser products include $\mathrm{C}_{2}$ radical, and $\mathrm{CO}^{+}$and $\mathrm{O}^{+}$cations. Molecular oxygen and carbon dioxide are formed at concentrations less than $100 \mathrm{ppm}$.
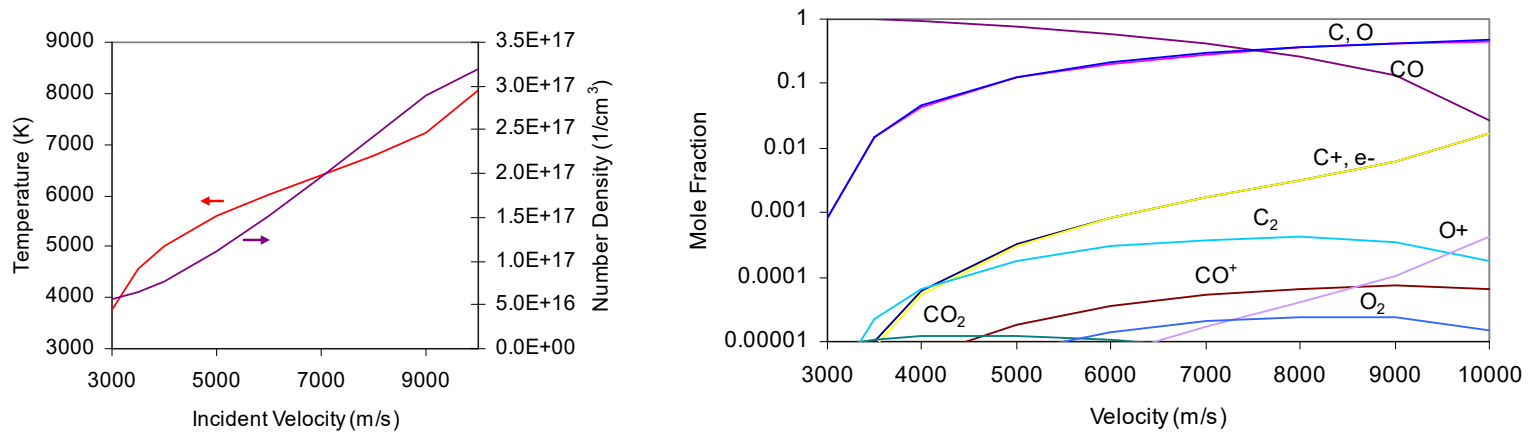

Figure 1. Equilibrium conditions for incident shocks in $\mathrm{CO}$ as a function of velocity at 0.25 Torr. (left) Total number density and temperature. (right) mole fractions.

The reaction mechanism postulated for the shock-heated gas is as follows. CO dissociation is initiated through heavy particle collision:

$$
\mathrm{CO}+\mathrm{M} \rightarrow \mathrm{C}+\mathrm{O}+\mathrm{M}
$$

Free oxygen and carbon atoms thus created enhance the $\mathrm{CO}$ dissociation rate through the exchange reactions:

$$
\begin{aligned}
& \mathrm{CO}+\mathrm{O} \rightarrow \mathrm{C}+\mathrm{O}_{2} \\
& \mathrm{CO}+\mathrm{C} \rightarrow \mathrm{C}_{2}+\mathrm{O}
\end{aligned}
$$

The $\mathrm{C}_{2}$ and $\mathrm{O}_{2}$ species then dissociate through heavy particle collisions:

$$
\begin{aligned}
& \mathrm{O}_{2}+\mathrm{M} \rightarrow \mathrm{O}+\mathrm{O}+\mathrm{M} \\
& \mathrm{C}_{2}+\mathrm{M} \rightarrow \mathrm{C}+\mathrm{C}+\mathrm{M}
\end{aligned}
$$

Ionization reactions, particularly with atomic carbon, will become significant as velocity/temperature rises, forming free electrons. At such conditions, electron impact may begin to drive the dissociation process.

\section{Results}

Seventeen shots in pure $\mathrm{CO}$ were obtained at an initial pressure of 0.25 Torr. It is deemed that 15 of the shots contain potentially useful data, with the other shots suffering from either low test time or missed camera triggers. The velocity range of useful data thus spans $3.4-9.5 \mathrm{~km} / \mathrm{s}$. This data set, along with data obtained at $0.10 \mathrm{Torr}$, and tests in pure $\mathrm{CO}_{2}$ and $\mathrm{CO}_{2} / \mathrm{Ar}$ mixtures will be archived on data.nasa.gov. Below, the general characteristics of the radiance are summarized first, followed by analysis of extracted temperature trends, then comparisons of spectral and spatially resolved radiance in the vacuum ultraviolet, infrared and visible regions.

\section{A. Radiance Summary}

The plot of spectral radiance as a function of the range of velocities is shown in Figure 2 for all four spectral ranges measured. Position shown is the position on the imaging window. Shock locations are at approximately $\mathrm{x}=2$ $\mathrm{cm}$. The trend versus position is subject to blurring due to instrument spatial resolution and minimum measurable radiances determined by the spectrometer noise floor [17]. The magnitude of VUV radiance increases by three orders of magnitude from 4 to $9 \mathrm{~km} / \mathrm{s}$. The radiance in the ultraviolet $(190-350 \mathrm{~nm})$, which is also mostly attributable to the $\mathrm{CO} 4^{\text {th }}$ Positive band, changes by a similar amount. The steady radiance from $\mathrm{C}_{2}$ Swan bands $(480-890 \mathrm{~nm})$ increases by $\sim 50 \mathrm{x}$ across the velocity range, though the non-equilibrium peak is almost an order of magnitude higher. The infrared signal has a low signal to noise ratio, but the magnitudes are fairly similar across all the tests. Above around $6 \mathrm{~km} / \mathrm{s}$, the non-equilibrium overshoot shows weak variation with velocity, but the decay behind the peak trends toward different values depending on velocity. The rate of decay does not appear drastically different versus velocity. 

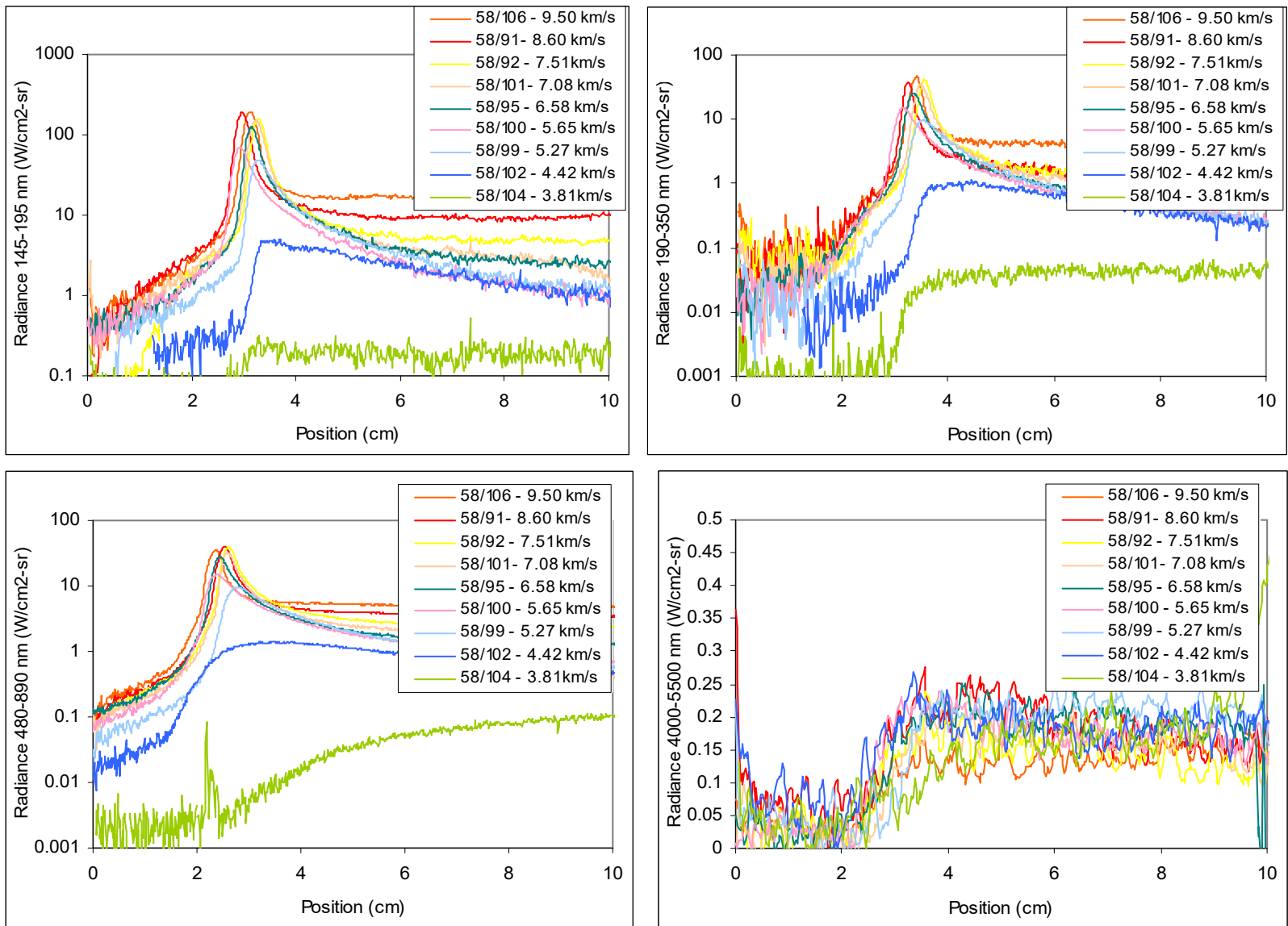

Figure 2. Radiance versus position for nine CO tests from $3.8-9.5 \mathrm{~km} / \mathrm{s}$ over the four spectral ranges measured.

\section{B. Determination of $\mathrm{CO}$ dissociation rate}

In previous work, we derived the space of valid solutions for low-speed shocks in $\mathrm{CO}_{2}$ [6]. This approach is based on the consideration that certain quantities must be conserved across an ideal $1 \mathrm{D}$ shock. This leads to a range of valid solutions which in general may be described as an $n$-dimensional space, where $n$ is the degrees of freedom. Combinations of density, temperature, etc. that lie outside of this space would not satisfy the conservation equations and thus are not considered to be physically allowed at any point behind the shock. The conserved quantities include density of individual atoms, momentum and specific total enthalpy. Conservation of mass is implied by conservation of atoms. It is possible to derive through the atom conservation equations a constancy of stoichiometry, which means that the atomic ratio of the mixture does not change across nor following the shock. (This neglects the possibility for differential diffusion to cause separation of species.) If we limit the CO products to $\mathrm{C}, \mathrm{O}, \mathrm{C}_{2}$ and $\mathrm{O}_{2}$ (i.e. neglecting ionization or recombination to $\mathrm{CO}_{2}$ and higher $\mathrm{C}_{\mathrm{n}}$ ) these equations may be written as:

$$
\begin{gathered}
n_{C O}+n_{C}+2 n_{C_{2}}=\frac{\rho_{0} v_{0}}{M_{C O} v_{0}} \\
n_{C}+2 n_{C_{2}}=n_{O}+2 n_{O_{2}} \\
\sum n_{i}\left(R T+M_{i} v^{2}\right)=p_{0}+\rho_{0} v_{0}^{2} \\
\sum n_{i}\left(h_{i}(T)+M_{i}\left(\frac{1}{2} v^{2}-h_{0}-\frac{1}{2} v_{0}^{2}\right)\right)=0
\end{gathered}
$$

This set of four equations has seven unknowns (five densities, temperature and velocity), which means that the space of valid solutions has three degrees of freedom, and is thus three dimensional. A set of constraints on the space of valid solutions is enforced by requiring number densities to be non-negative. Each one of these five constraints forms a plane that bounds the space of valid solutions. Four of the bounding planes, corresponding to 
zero density of each product species, intersect at a single point that is the frozen solution. Four pairs of planes have intersections with one degree of freedom, forming the edges of the 3-d space, and emanating from the frozen point. Certain planes may not intersect elsewhere (e.g. $\mathrm{n}_{\mathrm{C}}=\mathrm{n}_{\mathrm{C} 2}=0$ only at the frozen point) and the $\mathrm{n}_{\mathrm{CO}}=0$ plane may or may not be intersected, depending on the value of $\mathrm{v}_{0}$. Additional constraints are imposed by equilibrium, in that any single reaction could not progress past its equilibrium value. The equilibrium condition of any of five reactions discussed in Sect. II introduces an additional equation, so is described with two degrees of freedom. Therefore, bounds to the solution based on reaction equilibrium are planes in the three-dimensional space, and there are five such planes. All equilibrium planes intersect at the equilibrium solution, which is the final state of the shock.
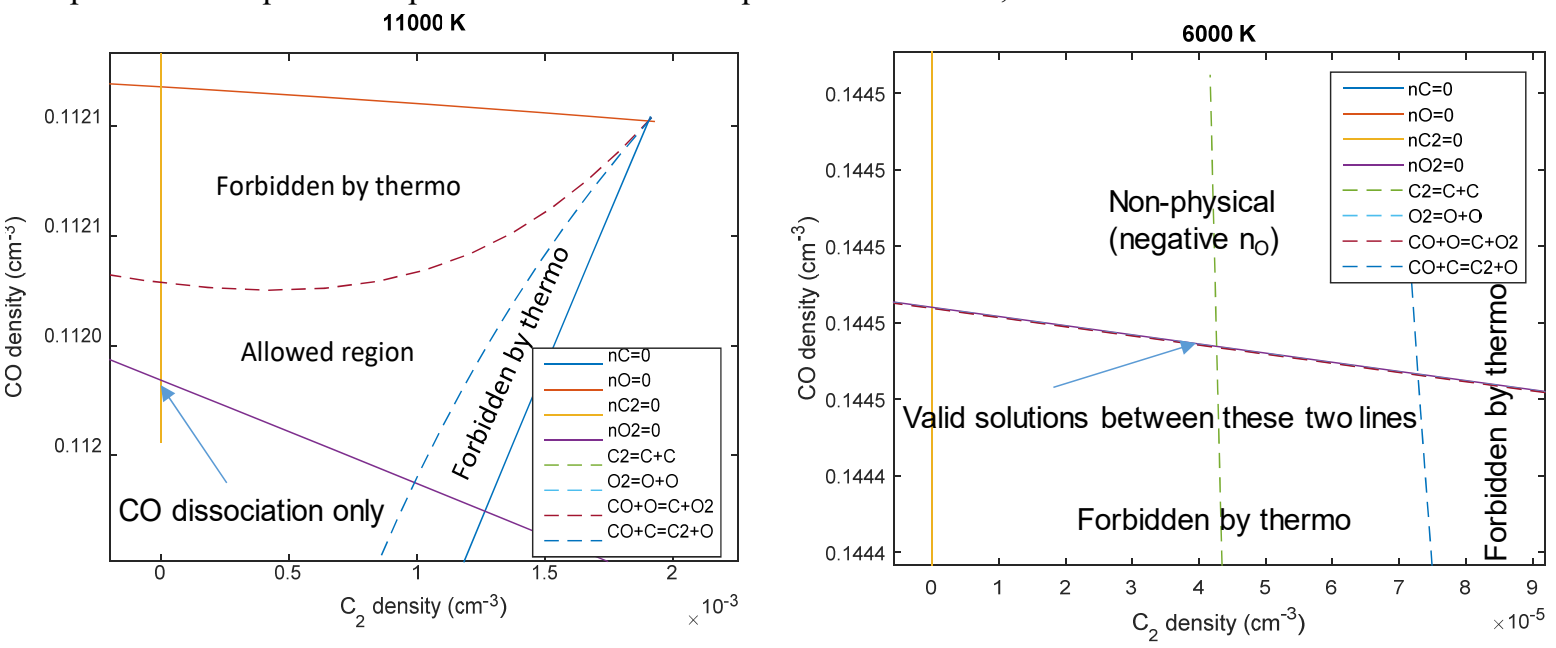

Figure 3. Valid solutions to the shock equations for a condition of $5.65 \mathrm{~km} / \mathrm{s}$ and $33 \mathrm{~Pa}$. The solution ranges on the left are for $11,000 \mathrm{~K}$ and on the right for $6,000 \mathrm{~K}$.

Figure 3 shows two cuts through the space of valid solutions for a shock at $5.65 \mathrm{~km} / \mathrm{s}$ and $33 \mathrm{~Pa}(0.25 \mathrm{Torr})$, where the degrees of freedom are chosen to be $\mathrm{CO}$ density, $\mathrm{C}_{2}$ density and temperature. Figure 3(a) is taken at $11,000 \mathrm{~K}$, close to the frozen solution. This solution is bounded by four lines that each represents zero number density of one of the products of $\mathrm{CO}$ dissociation. The range of allowed $\mathrm{CO}$ densities is very narrow, with only a $0.1 \%$ variation allowed. In the case of dissociation of $\mathrm{CO}$ through reaction (1), the only possible reaction at the onset of dissociation, the solution would lie in the lower left hand corner where $\mathrm{n}_{\mathrm{C} 2}=\mathrm{n}_{\mathrm{O} 2}=0$. At this temperature, recombination of $\mathrm{C}_{2}$ and $\mathrm{O}_{2}$ is disfavored thermodynamically. Curves representing the equilibrium of these processes lie nearly on top of the $\mathrm{n}_{\mathrm{C} 2}=0$ and $\mathrm{n}_{\mathrm{O} 2}=0$ boundaries. $\mathrm{C}_{2}$ and $\mathrm{O}_{2}$ may be created by exchange, however this process can not pass the equilibrium boundary shown by the dashed lines in the plot, which further restricts the possible solutions. As the temperature is lowered, these equilibrium limits collapse inward, reducing the space of valid solutions further, constraining the solution to lie very near to $\mathrm{n}_{\mathrm{O} 2}=0$ line, reducing the effective degrees of freedom to two. This is seen in Figure $3(\mathrm{~b})$ at $6,000 \mathrm{~K}$, where the $\mathrm{CO}$ density is constrained to within 4 significant digits. The $\mathrm{C}_{2}$ concentration has a range of allowed densities along this line, bounded between zero and the equilibrium of the exchange reaction.
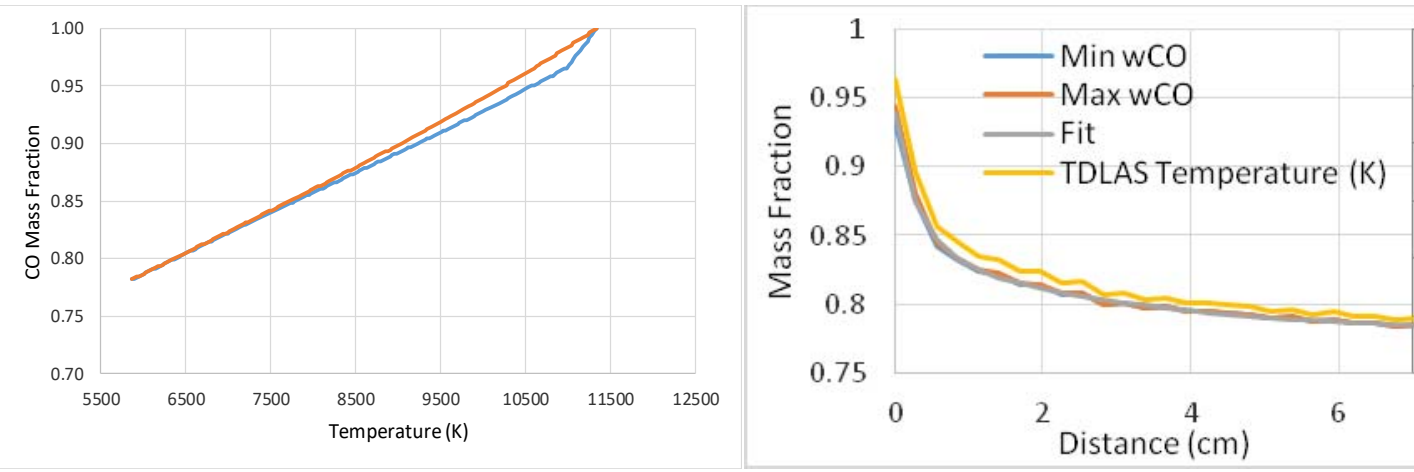

11000

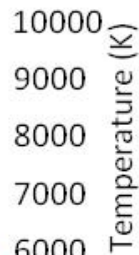

5000

Figure 4. Analysis of valid solutions at $5.65 \mathrm{~km} / \mathrm{s}$ and $0.25 \mathrm{torr}$. (left) The range of mass fractions allowed as a function of temperature. (right) mass fraction vs distance obtained from temperature vs distance curve 
The utility of the foregoing analysis is that it allows the density of $\mathrm{CO}$ to be expressed as a nearly single valued function of temperature. The curve of Figure 4(a) shows the range of allowed CO mass fractions as a function of temperature for the condition of $5.65 \mathrm{~km} / \mathrm{s}$. Using this curve, the temperature measurement behind the shock can be used to determine the mass fraction of $\mathrm{CO}$ at that position (assuming thermal equilibrium). This is shown in Figure 4(b) which has co-plotted the temperature measured by TDLAS and the corresponding minimum and maximum mass fractions. It is seen that the minimum and maximum mole fractions nearly coincide. The trend of mole fraction versus distance behind the shock may now be analyzed to obtain reaction rate data. The reaction rate can be found using the 1-D species mass conservation equation for $\mathrm{CO}$ in shock relative co-ordinates:

$$
\frac{d \omega_{C O}}{d x}=\frac{M_{C O} r_{C O}}{\rho_{0} v_{0}}
$$

Considering the reactions enumerated above, the rate of $\mathrm{CO}$ reaction may be written as

$$
\frac{r_{C O}}{n_{C O} n_{t o t}}=k_{1}+k_{2} x_{O}+k_{3} x_{C}
$$

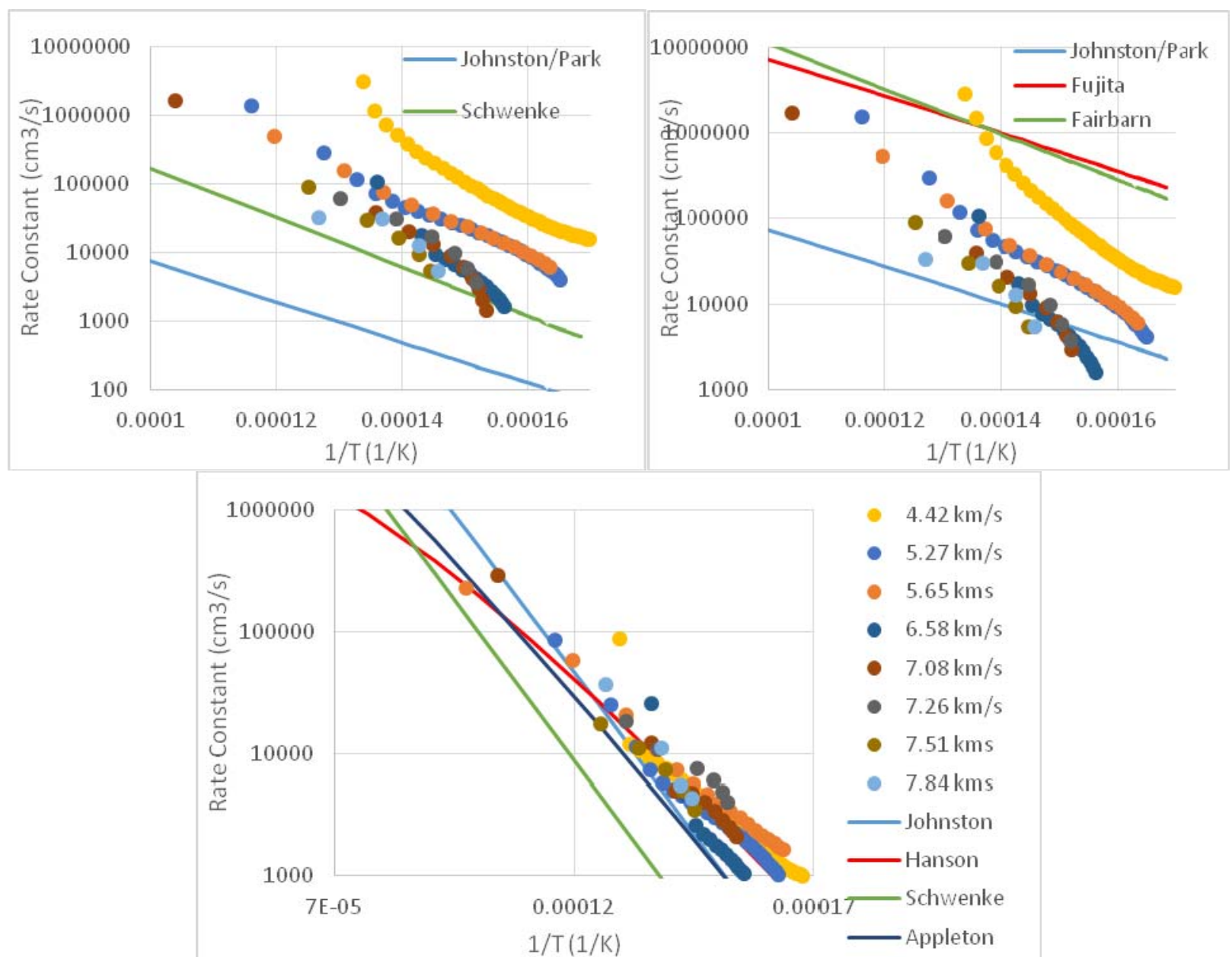

Figure 5. Extracted rate constants assuming reaction is controlled by (a) $\mathrm{O}$ atom exchange, (b) $\mathrm{C}$ atom exchange or (c) $\mathrm{CO}$ dissociation

if only reactions in the forward direction are considered. Correction factors for reverse reaction may be determined using the equilibrium constants as a function of temperature, but they tend to impact the analysis very close to equilibrium where the reaction rate becomes indeterminate. The total number density and CO mass fractions are known from the preceding analysis, thus the reaction rate coefficient may be determined and plotted in the limit of exchange and dissociation dominated reaction. The corresponding plot for conditions varying from $4-8 \mathrm{~km} / \mathrm{s}$ are shown in Figure 5. For comparison, $\mathrm{CO}$ dissociation and exchange rates from different literature sources are also shown[1, 19-24]. Rates derived assuming that exchange dominates fail to collapse to a single curve, suggesting that 
the rate is independent of $\mathrm{O}$ or $\mathrm{C}$ mole fraction. It is noted that the rates shown are based upon the largest allowed atom mole fraction for the condition, and thus represent a lower bound to the reaction rate. The rate with $\mathrm{CO}$ dissociation dominating collapse into a band that is very near to the rate measured by Hanson in 1974 [21]. Hanson's rate is given as:

$$
\mathrm{k}_{1}=7.99 \times 10^{38} \mathrm{~T}^{-5.5} \exp (-129,000 / \mathrm{T}) \mathrm{cm}^{3} / \mathrm{mol}-\mathrm{s}
$$

Rate coefficients at or above $\sim 10^{5} \mathrm{~cm}^{3} / \mathrm{s}$ using the current data set with a $0.5 \mu$ s data interval are difficult to estimate because the mass fraction derivative is based on the slope of the data from only one point. Thus the larger scatter at higher temperature leaves open to intepretation whether the high temperature range of Hanson's fit is necessarily consistent with the data.

The modified Arrhenius expression proposed by Hanson includes a very large negative temperature exponent which is not consistent with kinetic theory. It has been thus proposed [25] that the measured rate is actually that of a compound reaction. Various two step reaction pathways have been considered, including exchange with $\mathrm{C}$ [21], $\mathrm{O}$ [26] or $\mathrm{CO}$ [25] leading to the formation of $\mathrm{C}_{2}, \mathrm{O}_{2}$ or $\mathrm{CO}_{2}$, respectively, which then decomposes to products as the second step of the reaction. In building a kinetic model driven by any one of these reactions, however, it is found that the intermediate quickly reaches equilibrium and the process becomes driven by decomposition rate of the product $\mathrm{C}_{2}, \mathrm{O}_{2}$ or $\mathrm{CO}_{2}$. While these species may decompose relatively quickly, their equilibrium density is low enough that this pathway cannot explain the observed reaction rate. As an alternative to these theories, we propose the dissociation proceeds through an excited state of the $\mathrm{CO}$ molecule:

$$
\begin{aligned}
& \mathrm{CO}(\mathrm{X})+\mathrm{M} \leftrightarrow \mathrm{CO}^{*}+\mathrm{M} \\
& \mathrm{CO}^{*}+\mathrm{M} \leftrightarrow \mathrm{C}+\mathrm{O}+\mathrm{M}
\end{aligned}
$$

If the intermediate $\mathrm{CO}^{*}$ is assumed to reach a quasi-steady state, the effective compound reaction is given by:

$$
\begin{gathered}
k_{1, \text { eff }}=\frac{k_{14} k_{13}}{k_{-13}+k_{14}} \\
k_{1, \text { eff }}=\frac{k_{14} k_{13}}{\left(\frac{n_{C^{*}}}{n_{C O(X)}}\right)_{e q} k_{13}+k_{14}}
\end{gathered}
$$

There are two limiting solutions to the compound rate, shown in Figure 6(a). When the dissociation rate is large, excitation is the rate limiting step, and the effective rate is equal to the excitation rate. This rate will have a lower activation energy than dissociation and is therefore the limiting rate at high temperature. When excitation dominates, dissociation is the rate limiting step and the effective rate is the dissociation rate times the equilibrium coefficient, which has the same activation energy as $\mathrm{CO}$ dissociation:

$$
k_{1, \text { eff }}=\left\{\begin{array}{rr}
\left(\frac{n_{C O(X)}}{n_{C O^{*}}}\right)_{e q} k_{14} \propto \exp \left(-E_{1} / R T\right) & T \rightarrow 0 \\
k_{13} \propto \exp \left(-E_{13} / R T\right) & T \rightarrow \infty
\end{array}\right.
$$
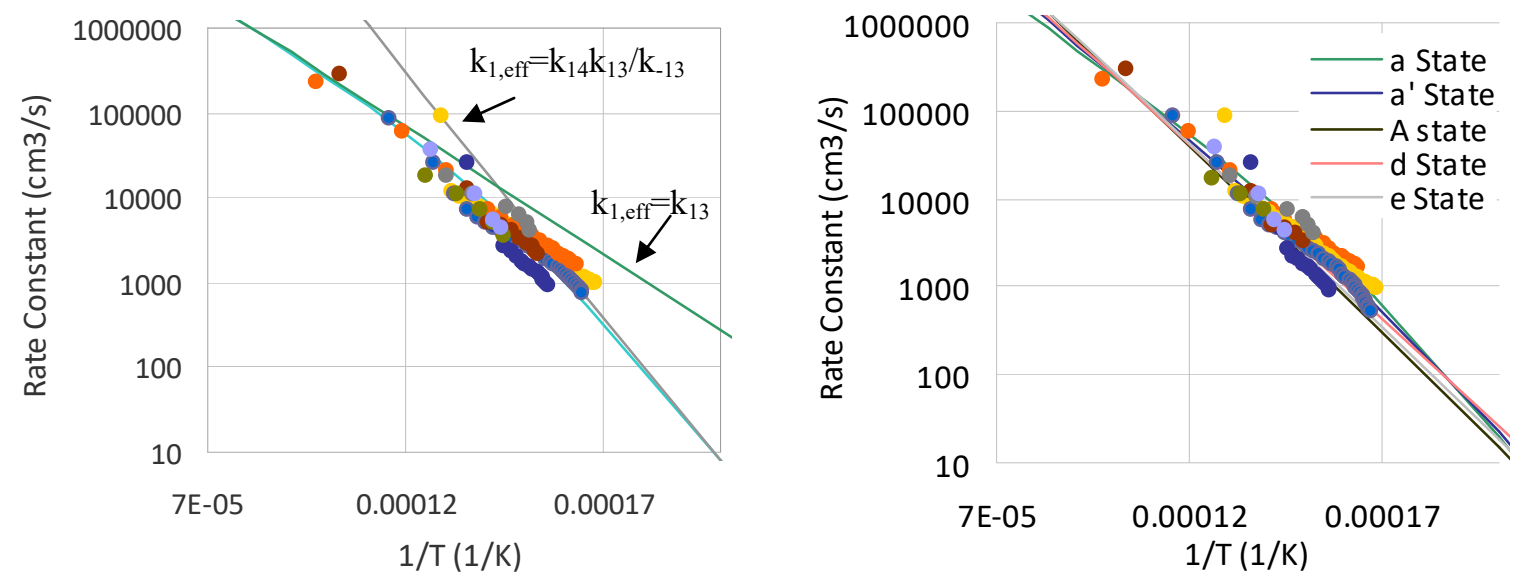

Figure 6. (a) Limiting rates for compound reaction mechanism, (b) as fit with different intermediate states 
It is not possible to uniquely determine the intermediate state from the available data. The rate constants of Schwenke are based upon quantum mechanic calculations of dissociation from the ground state of CO [23]. The quasi-steady state process of vibrational excitation has been examined by Venturi and Panesi [27]. Rates obtained in both of these studies are significantly lower than rates reported here, suggesting dissociation does not proceed through vibrational levels of the ground electronic state. Several candidate excited states may be identified, with obvious candidates being the metastable levels a, a', d, e. Two parameter fits of the form:

$$
\begin{aligned}
& k_{13}=A_{13} T^{1 / 2} \exp \left(-\frac{E_{13}}{R T}\right) \\
& k_{14}=A_{14} T^{1 / 2} \exp \left(-\frac{E_{1}-E_{13}}{R T}\right)
\end{aligned}
$$

have been produced for each of the four metastable states and for the A state of $\mathrm{CO}$. All five states plausibly explain the data (Figure 6(b)). The pre-factors required for dissociation range from $4 \times 10^{11}-1 \times 10^{13} \mathrm{~cm}^{3} / \mathrm{s}$. For comparison, Park had proposed dissociation pre-factors of around $4 \times 10^{10} \mathrm{~cm}^{3} / \mathrm{s}$ [28]. This proposal was based on a scaling of the overall CO dissociation rate, so is speculative and not based upon observation. Nevertheless, the large disagreement between the high end of the rate constants, which correspond to the $\mathrm{A}, \mathrm{d}$ and e states of $\mathrm{CO}$, and this proposed rate suggests dissociation is likely not driven through these more highly excited states. However, dissociation through the a and a' states of CO may be more plausible, and it is likely that the dissociation process would proceed through some combination of these states. There are no direct measurements of the excitation process available for comparison, however the reverse process of quenching has been measured for several excited levels of CO. Quenching is primarily measured at $300 \mathrm{~K}$, while the processes involved here range from $5000-12000 \mathrm{~K}$. Assuming a $\mathrm{T}^{1 / 2}$ scaling, the inferred quenching rates at $300 \mathrm{~K}$ from this data would need to be on the order of $10^{-11} \mathrm{~cm}^{-3} \mathrm{~s}$, which is about an order of magnitude lower than measured quenching rates [28]. The discrepancy could be reconciled by assuming a different temperature scaling. A temperature exponent of -0.2 is found to both reproduce the data and the quenching rate at $300 \mathrm{~K}$. This new fit reduces the rate of dissociation required so that it is now better than 1 order of magnitude agreement with Park's estimated rate.

These relationships imply that the electronically excited state of $\mathrm{CO}$ must be fully excited to drive dissociation at low temperatures. This result at first appears counter-intuitive, as excited states are sparsely populated at low temperatures and thus often assumed to be negligible. However, at low temperatures the thermal energy is often not sufficient to overcome the reaction barrier; dissociation through the intermediate state allows dissociation to proceed through a multi-step process with lower individual energy barriers. The overall activation energy in the multi-step process is the sum of the two energy barriers, thus equal to the dissociation energy. Consideration of only ground electronic state has appeared to work well for predicting $\mathrm{N}_{2}$ dissociation from quantum energy surfaces $[29,30]$. One important difference between $\mathrm{CO}$ and $\mathrm{N}_{2}$ are the energies of their metastable levels relative to the dissociation limit. The energy of the first metastable of CO is $48,700 \mathrm{~cm}^{-1}$, which is nearly half of the dissociation energy of $89,500 \mathrm{~cm}^{-1}$. The energies of the first $\mathrm{N}_{2}$ metastable and $\mathrm{N}_{2}$ dissociation limit are much closer together, at 69,200 $\mathrm{cm}^{-1}$ and $78,700 \mathrm{~cm}^{-1}$ respectively. Thus, the use of ground electronic states to determine dissociation rates may require re-examination for molecules with low-lying metastables such as $\mathrm{CO}$ and $\mathrm{O}_{2}$. 

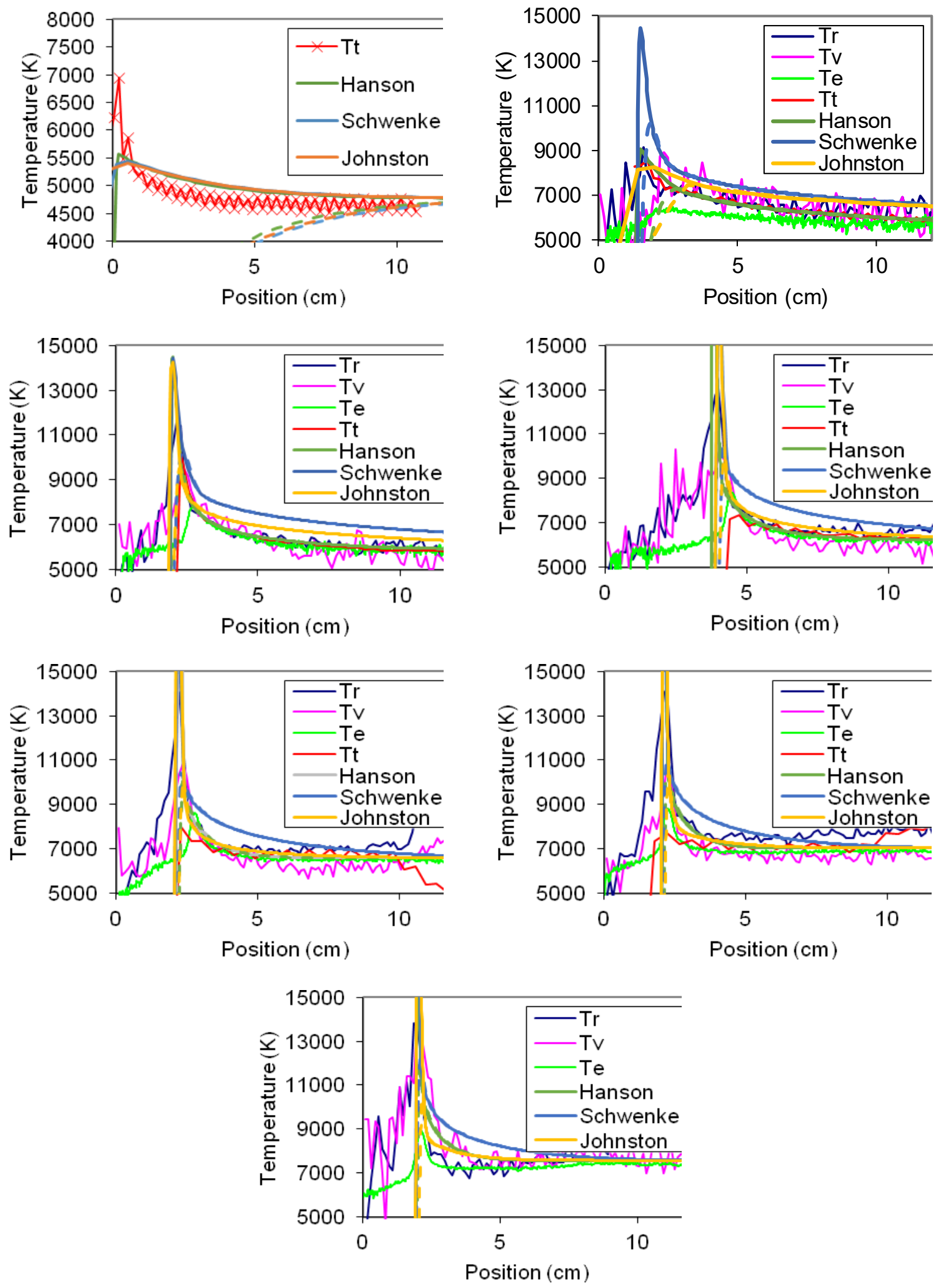

Figure 7. Comparison of temperature relaxations measured experimentally and predicted. Predicted vibrational temperatures are shown as dashed lines. The conditions correspond to velocities of (from left-toright, top-to-bottom) $3.4 \mathrm{~km} / \mathrm{s}, 4.4 \mathrm{~km} / \mathrm{s}, 5.7 \mathrm{~km} / \mathrm{s}, 6.6 \mathrm{~km} / \mathrm{s}, 7.5 \mathrm{~km} / \mathrm{s}, 8.6 \mathrm{~km} / \mathrm{s}$ and $9.5 \mathrm{~km} / \mathrm{s}$. 


\section{Analysis of post-shock temperatures}

The proposed rates are tested against temperature data for a range of conditions and shown in Figure 7, using a blunt-body analogue of the 1D shock to obtain a predicted relaxation profile [31]. Shown are the rotational and vibrational temperatures extracted from $\mathrm{C}_{2}$ spectra, the translational temperature determined from TDLAS and the electronic temeperature of $\mathrm{CO}$ based on Planck limited radiation in the vacuum ultraviolet[3]. Temperatures in front of the shock are biased by instrument resolution so are not interpreted as true shock temperatures. At $3.4 \mathrm{~km} / \mathrm{s}$, reactions are insignificant and all rate coefficients give the same result. The electronic excitation is insufficient to produce observable emission from $\mathrm{CO}$ and $\mathrm{C}_{2}$ and thus the only temperature presented is the translational temperature. The only trend in temperature is due to rovibrational mode separation, which is not predicted well. This trend is based on Millikan-White relaxation formulae as summarized by Park, et al. [19]. The measurement shows a significant overshoot and faster relaxation in comparison to prediction. At $4.4 \mathrm{~km} / \mathrm{s}$, reactions and electronic excitation are observed. The electronic temperature does not reach the ro-vibrational temperature, possibly indicating the $\mathrm{CO}$ radiation is not fully optically thick. The Hanson rate [21] goes right through the data, while the Schwenke [23] and Johnston [1] rates overpredict the temperature due to too little dissociation. The vibrational temperature predicted is shown by the dashed line and agrees fairly well with the vibrational temperature trend from the data. At $5.7 \mathrm{~km} / \mathrm{s}$, the three reactions rates predict a similar peak temperature. This temperature exceeds the measured rotational temperature, however is obtained on a shorter time scale than can be determined by the instrument resolution. After the initial relaxation, the three rates plateau differently. As at $4.4 \mathrm{~km} / \mathrm{s}$, the slower dissociation rate at low temperature cause Johnston and Schwenke rates to overpredict the temperature, while the Hanson rate goes through the data. At 6.6 and $7.5 \mathrm{~km} / \mathrm{s}$, the Johnston and Hanson models begin to converge to each other, while the Schwenke rate is still too slow and overpredicts temperature. At $8.6 \mathrm{~km} / \mathrm{s}$, small differences between the Hanson and Johnston rates are observed after the fast initial relaxation due to the lower dissociation rate of Hanson at elevated temperature. The noise in the data does not allow a higher confidence to be assigned to either one of these rates at this condition. At $9.5 \mathrm{~km} / \mathrm{s}$, the translational temperature data could not be obtained. The electronic and rotational temperatures display a faster relaxation to steady state than any rate model predicts. The somewhat slower vibrational relaxation may simply be an artifact of the methodology used to extract vibrational temperature. This fast relaxation may be a symptom of the role that ionization plays in the temperature profile at high shock speeds. The ionization mechanisms for $\mathrm{CO}$ and $\mathrm{C}$, including electron impact dissociation processes, requires further examination, and will not be addressed in this work. Predictions in this speed and temperature regime will be relevant for probe entries to Venus.

\section{CO Infrared Radiation}

The primary infrared feature is due to the fundamental vibrational transition of the $\mathrm{CO}$ molecule near $4.3 \mu \mathrm{m}$. Transitions in this range are also responsible for the absorption line used for TDLAS. The CO IR radiation behind the shock front is shown in Figure 8 for seven different shock velocities, and compared to predictions using different $\mathrm{CO}$ dissociation rates. In all these figures, position is that along the test section window, and the predicted data have been convolved with the spatial resolution function of the instrument. The models predict similar radiance trends until about $6 \mathrm{~km} / \mathrm{s}$ when the non-equilibrium overshoot begins to vary between the models. This overshoot is not apparent in the experimental data. The overshoot is correlated to the temperature trend discussed in the last section, which in turn is dependent upon the rate of $\mathrm{CO}$ dissociation. The larger dissociation rate at high temperature, as applied by Johnston, results in very little overshoot, even at $9.5 \mathrm{~km} / \mathrm{s}$. This may suggest a rate that matches that of Hanson at low temperature and Johnston at high temperature may best explain the data. Alternatively, the trend at high velocity may be attributed to the effect of electron impact dissociation of $\mathrm{CO}$, which is not treated in this model. Another general observation of the data is that the radiation is generally underpredicted at all conditions. 


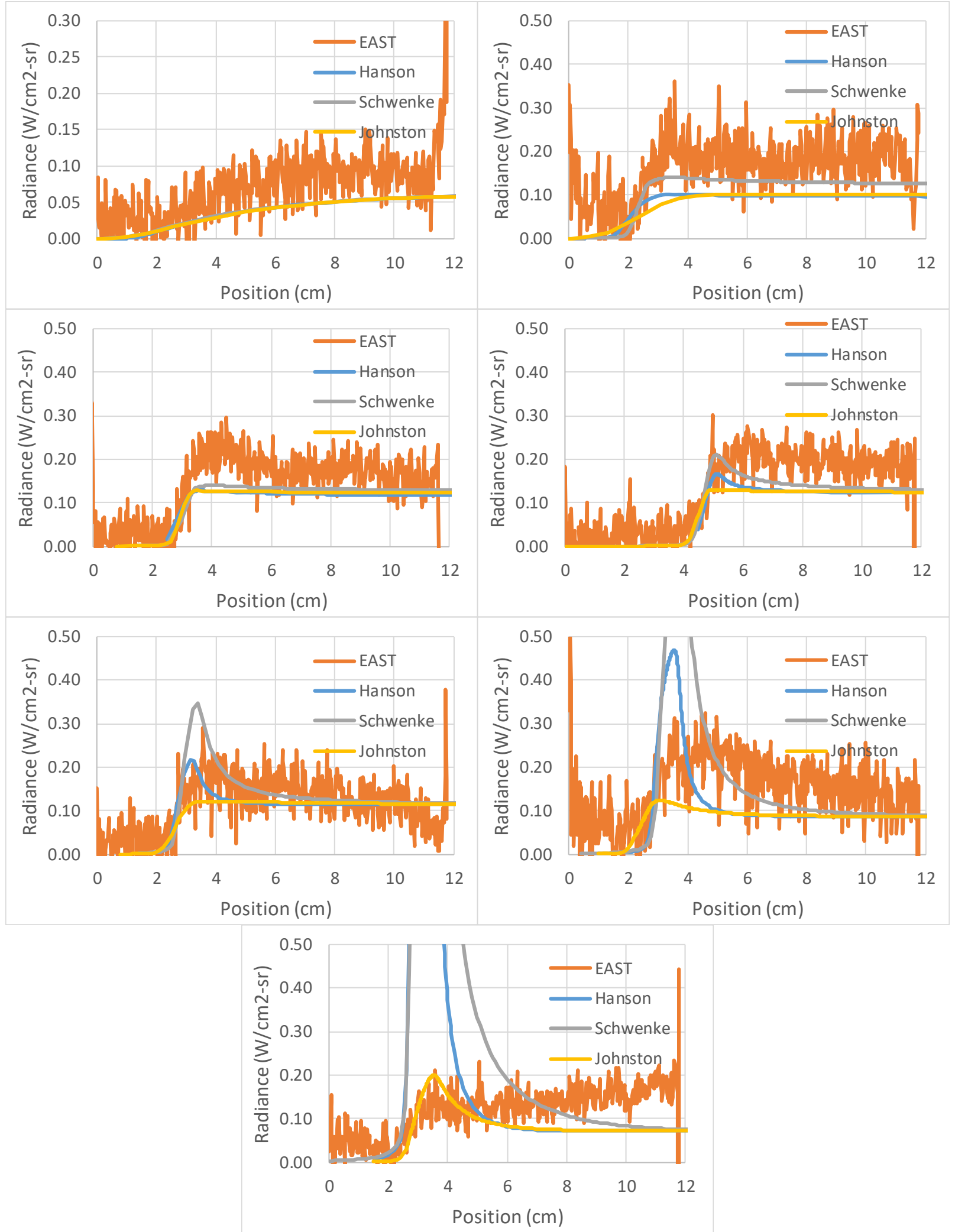

Figure 8. CO infrared radiation from $4000-5500 \mathrm{~nm}$ as a function of position on the spectrometer window and comparison to predictions based on different $\mathrm{CO}$ dissociation rates. The figures correspond to velocities of (from left-to-right, top-to-bottom) $3.4 \mathrm{~km} / \mathrm{s}, 4.4 \mathrm{~km} / \mathrm{s}, 5.7 \mathrm{~km} / \mathrm{s}, 6.6 \mathrm{~km} / \mathrm{s}, 7.5 \mathrm{~km} / \mathrm{s}, 8.6 \mathrm{~km} / \mathrm{s}$ and $9.5 \mathrm{~km} / \mathrm{s}$.

11

American Institute of Aeronautics and Astronautics 

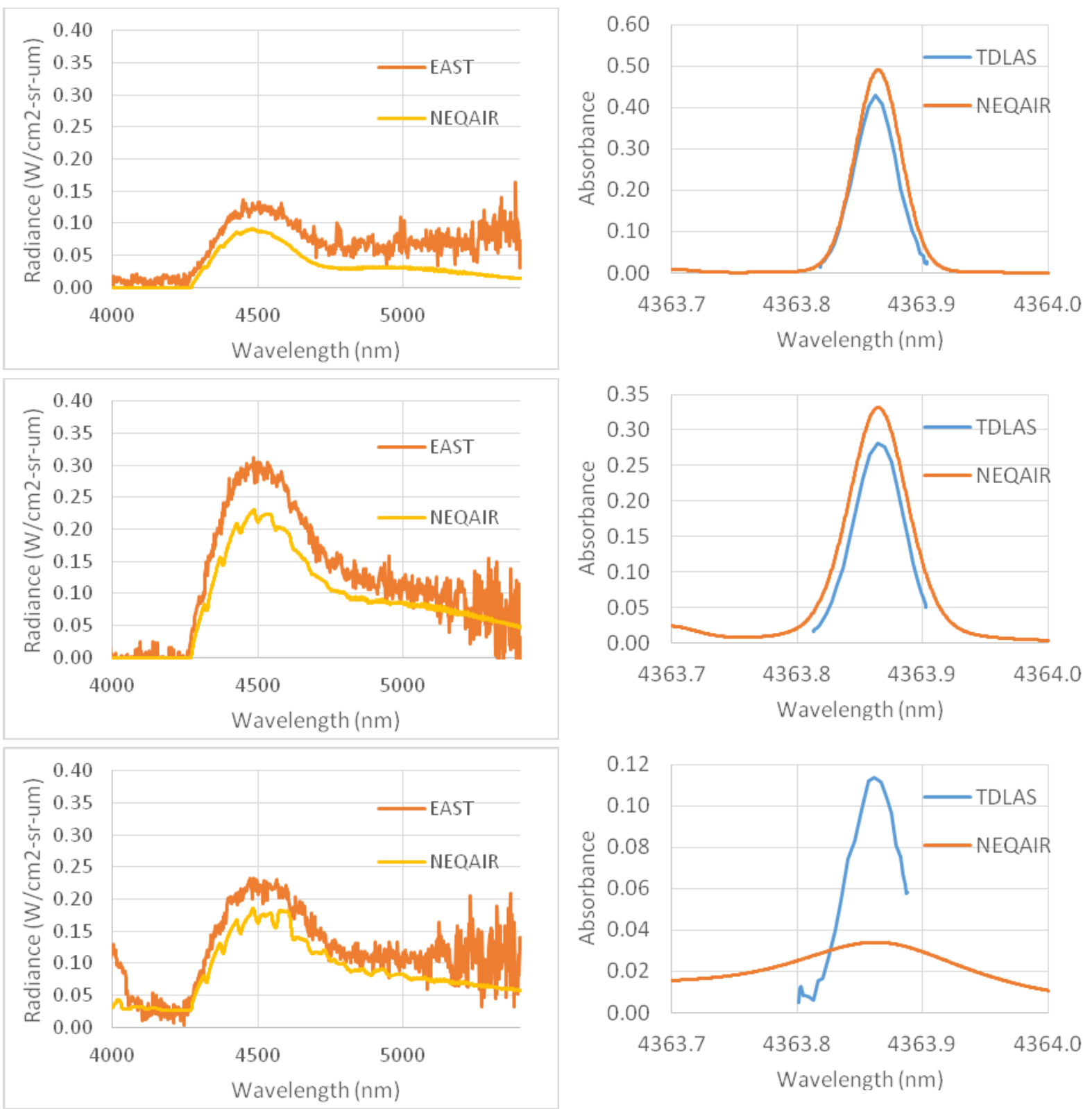

Figure 9. Comparison of measured to predicted spectral radiance (left) and laser absorption (right) at conditions of $3.4 \mathrm{~km} / \mathrm{s}, 5.7 \mathrm{~km} / \mathrm{s}$ and $8.6 \mathrm{~km} / \mathrm{s}$.

To examine the underprection, spectral data are examined at a distance of $\sim 4 \mathrm{~cm}$ from the shock front, where the radiance level is fairly steady, in Figure 9. The spectrum appears uniformly underpredicted by about $30 \%$ at all conditions. Comparisons of the TDLAS absorption lines at $4363.87 \mathrm{~nm}$ are shown on the right side of Figure 9 for the same tests. Absorption is generally overpredicted by $25-30 \%$. This trend is apparent in efforts to extract CO number density from the absorption lines, which consistently provided lower $\mathrm{CO}$ densities than are expected based on CFD or equilibrium analysis[15]. At the $8.6 \mathrm{~km} / \mathrm{s}$ condition, Stark broadening is overestimated by NEQAIR, producing a wide line that has blended with other adjacent lines. This is assumed to be an error in NEQAIR, as the Stark broadening coefficients for molecules are mere estimates.

To better understand the simultaneous underprediction of emission and overprediction of absorbance within the same test, it is useful to examine the relationships between these two quantities. The emission spectrum is described by:

12

American Institute of Aeronautics and Astronautics 


$$
I_{e}(\lambda)=\frac{h c d}{4 \pi \lambda} \sum A_{u l} n_{u} \phi\left(\lambda-\lambda_{u l}\right)
$$

assuming the radiation to be optically thin. The absorbance, defined as $a=-\ln \left(\mathrm{I}_{\mathrm{a}} / \mathrm{I}_{0}\right)$, is given by

$$
a(\lambda)=\frac{\lambda^{4} d}{8 \pi c} \sum A_{u l}\left(\frac{g_{u}}{g_{l}} n_{l}-n_{u}\right) \phi\left(\lambda-\lambda_{u l}\right)
$$

assuming the laser intensity is significantly larger than the emission intensity of the species being measured. For the experiments described, this has been verified by performing measurements without the laser present, and no signal is observed on the detector. The only spectroscopic parameter in both relationships is the Einstein coefficient, $A_{\mathrm{ul}}$. This value has been checked by evaluating several different linelists[32-38], and the variation between these lists and the NEQAIR implementation is found to be no more than 5\%. The alternative then is a misprediction of the upper and/or lower state densities. These quantities may be written as:

$$
\begin{aligned}
& n_{l}=g_{l} \exp \left(-\frac{E_{l}}{k T}\right) \frac{n_{C O}}{Q_{C O}} \chi_{l} \\
& n_{u}=g_{u} \exp \left(-\frac{E_{u}}{k T}\right) \frac{n_{C O}}{Q_{C O}} \chi_{u}
\end{aligned}
$$

where an overpopulation factor $\chi_{\mathrm{i}}$ is introduced into each equation to account for deviations from a Boltzmann distribution. The predicted spectra are based upon no overpopulation (i.e. overpopulation factor of 1). The degeneracies $\mathrm{g}_{\mathrm{i}}$ and energies $\mathrm{E}_{\mathrm{i}}$ are well known for each individual line. The concentration $\mathrm{n}_{\mathrm{CO}}$ is dependent upon the kinetic model employed, but is also constrained by the conservation equations as discussed in the previous section. For most of the spectra shown, values of $\mathrm{n}_{\mathrm{CO}}$ predicted by the models are nearly the same at a distance of $4 \mathrm{~cm}$ from the shock, so the result is not likely to be due to errors in this quantity. Errors in the partition function would impact both spectra in the same direction. An overpopulation factor of $\chi_{\mathrm{u}}=1.3$ would match the emission spectra, if this factor were applied to every upper state. However, a significant deviation from the Boltzmann distribution would necessitate the evaluation and application of a non-Boltzmann partition function:

$$
Q_{C O}=\sum g_{i} \exp \left(-\frac{E_{i}}{k T}\right) \chi_{i}
$$

To compensate this effect, the overpopulation factor would need to be increased further to approximately 1.9 to explain the emission data. The impact of increasing upper state population and subsequent increase in partition function would serve to reduce the predicted absorbance by more than a factor of 2, putting it well below the experimental measurement. This would then require a significant over-population of the lower state, which in turn requires re-evaluation of the partition function, which would further distort the required distribution. This combination of adjustments quickly becomes implausible, suggesting the deviation cannot be reasonably explained by a non-Boltzmann distribution.

With most obvious physical causes for discrepancy ruled out, it is tempting to ascribe the discrepancy to experimental biases, though these biases would need to apply in opposite directions to two independent measurements of the same flow. McGuire and Laux have observed relatively consistent measurements of emission and absorption of $\mathrm{CO}$ in a plasma torch at temperatures near $5000 \mathrm{~K}$, under high resolution [39]. In their measurements, the density of $\mathrm{CO}$ was not known ahead of time, so the data cannot be used as a check on the linestrength values. Underpredictions of absorbance using the HITRAN linelist at low resolution has been observed at temperatures from 1200-2700K, and pressures from 0.5-3 bar [40]. Experiments below 1200K were well matched. The commonality between Ref. [40] and the current results in emission are that they are measurements of emission/absorption over the entire band, while the overprediction of the TDLAS absorbance applies to an individual line. Possibly, if additional levels were introduced to the HITRAN database, this would have the effect of increasing the partition function and thus reducing the absorbance of a single line. At the same time, it would contribute additional lines to the summed emission/absorption spectrum, which may have the effect of increasing the band emission and integrated radiance. This possibility would require further investigation. It is noted that the impact of infrared radiation from $\mathrm{CO}$ is going to be insignificant as a heating mechanism for vehicles entering the atmospheres of Mars or Venus, however, inaccuracies in the partition function or energy levels of $\mathrm{CO}$ will have a wider implication for predicting the thermodynamics and reaction rates of $\mathrm{CO}$ in $\mathrm{CO}_{2}$ flows. 


\section{E. $\mathrm{C}_{2}$ Radiation}

Radiation from the $\mathrm{C}_{2}$ molecule is observed at velocities as low as $3.8 \mathrm{~km} / \mathrm{s}$ when working with pure $\mathrm{CO}$. The primary radiation feature is from the Swan band $\left(\mathrm{d}^{3} \Pi_{\mathrm{g}}-\mathrm{a}^{3} \Pi_{\mathrm{u}}\right)$ from 480-680 nm and lower (the region from 350-480 $\mathrm{nm}$ was not measured in these tests). Additional $\mathrm{C}_{2}$ radiation features are observed at $232 \mathrm{~nm}$ (Mulliken band, $\mathrm{D}^{1} \Sigma_{\mathrm{u}}^{+}-\mathrm{X}^{1} \Sigma_{\mathrm{g}}{ }^{+}$) and near $340 \mathrm{~nm}$ (Deslandres-D'Azambuja band, $\mathrm{C}^{1} \Pi_{\mathrm{g}}-\mathrm{A}^{1} \Pi_{\mathrm{u}}$ ), though the following discussion will focus on the Swan band.

As discussed, there are two rates that control the $\mathrm{C}_{2}$ concentration in this system: dissociation and exchange. A survey of different literature rates for these two processes is shown in Figure 10. The rates for $\mathrm{C}_{2}$ dissociation employed by Park [19] and Johnston [1] are very similar, but about an order of magnitude less than other $\mathrm{C}_{2}$ dissociation rates in the literature. The Park rate originates from the measurements of Beck and Mackie [41]. Separate measurements by Fairbarn [42] or Kruse[43] were inconsistent with the rates reported by Beck and Mackie, and Fujita performed a fit of these plus one other data set to obtain an average rate constant [20]. Johnston used the activation energy and exponent obtained by Fujita and scaled the prefactor to obtain a rate similar to Park's.
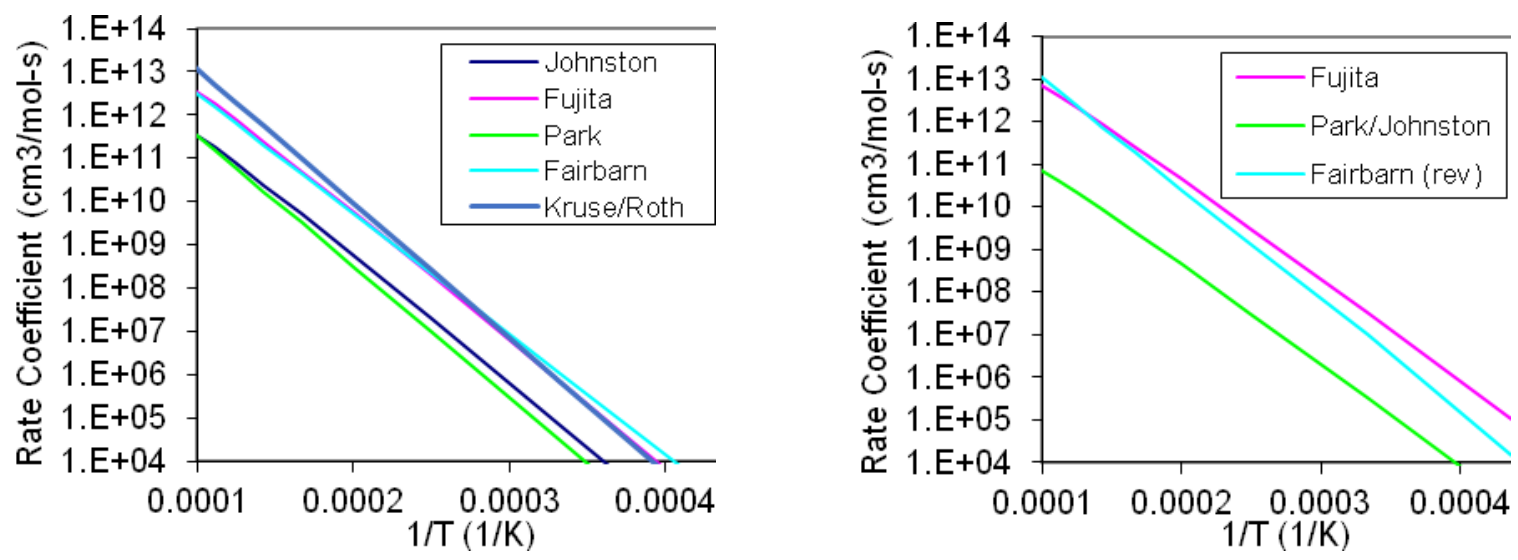

Figure 10. Literature rates for (a) heavy particle dissociation of $C_{2}$ and (b) $\mathrm{CO} / \mathrm{C}$ exchange to form $\mathrm{C}_{2}$.

The rate for $\mathrm{CO} / \mathrm{C}$ exchange recommended by Park [19] was based upon his own fit to Hanson's data[21], and is likely dependent upon other choices of modeling parameters, such as the previously discussed $\mathrm{C}_{2}$ and $\mathrm{CO}$ dissociation rates. Fairbarn reported the reverse rate of the exchange reaction at a single temperature[24], and Fujita scaled Park's reaction rate to match[20]. The Fairbarn curve shown in Figure 10(b) is the exchange rate determined by reversing Fairbarn's rate with no assumed temperature dependence. For purposes of calculating with Fairbarn's rate, the reverse rate is modeled using a constant rate coefficient; the forward rate will be determined by the CFD code based on detailed balance. The rate given by Fairbarn is approximately two orders of magnitude larger than that employed by Park.
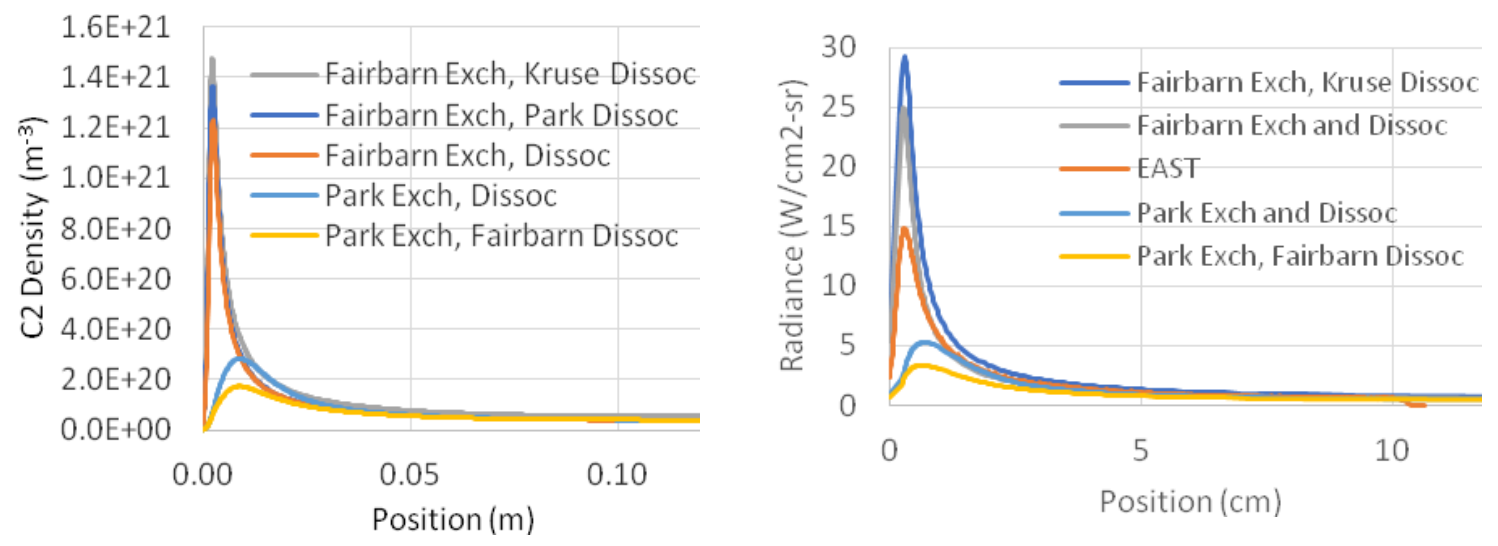

Figure 11. Impact of different $C_{2}$ reaction (a) $C_{2}$ density and (b) $C_{2}$ radiance at $5.65 \mathrm{~km} / \mathrm{s}$.

The impact of the rate coefficients is shown in Figure 11 for the shock condition of $5.65 \mathrm{~km} / \mathrm{s}$. A combination of dissociation rates from Kruse, Fairbarn and Park with the exchange rates of Park and Fairbarn are shown. The 
exchange rate is the most impactful, with the Park exchange causing a more gradual build-up of $\mathrm{C}_{2}$ concentration in comparison to Fairbarn's exchange rate. Using Fairbarn's rate produces a sharp peak in $\mathrm{C}_{2}$ concentration near the shock front, which is more consistent with the experimental data (Figure 11b). Altering the dissociation rate has lesser impact, modulating the magnitude of $\mathrm{C}_{2}$ concentration but not the overall shape of the curve. While the radiance profile is better matched with Fairbarn's exchange rate, the peak value of radiance is overpredicted. Employing a slower dissociation rate, such as Park's, would serve to worsen the overprediction. Introduction of a non-Boltzmann model for $\mathrm{C}_{2}$ is expected to reduce the radiance in non-equilibrium. The current results are based upon a Boltzmann distribution of $\mathrm{C}_{2}$ electronic states. It would thus be more prudent to examine non-Boltzmann models for $\mathrm{C}_{2}$ than to consider further adjustment to the dissociation rate. For the moment, the rates of Fairbarn for both exchange and dissociation appear to reproduce the data well and are carried forward.
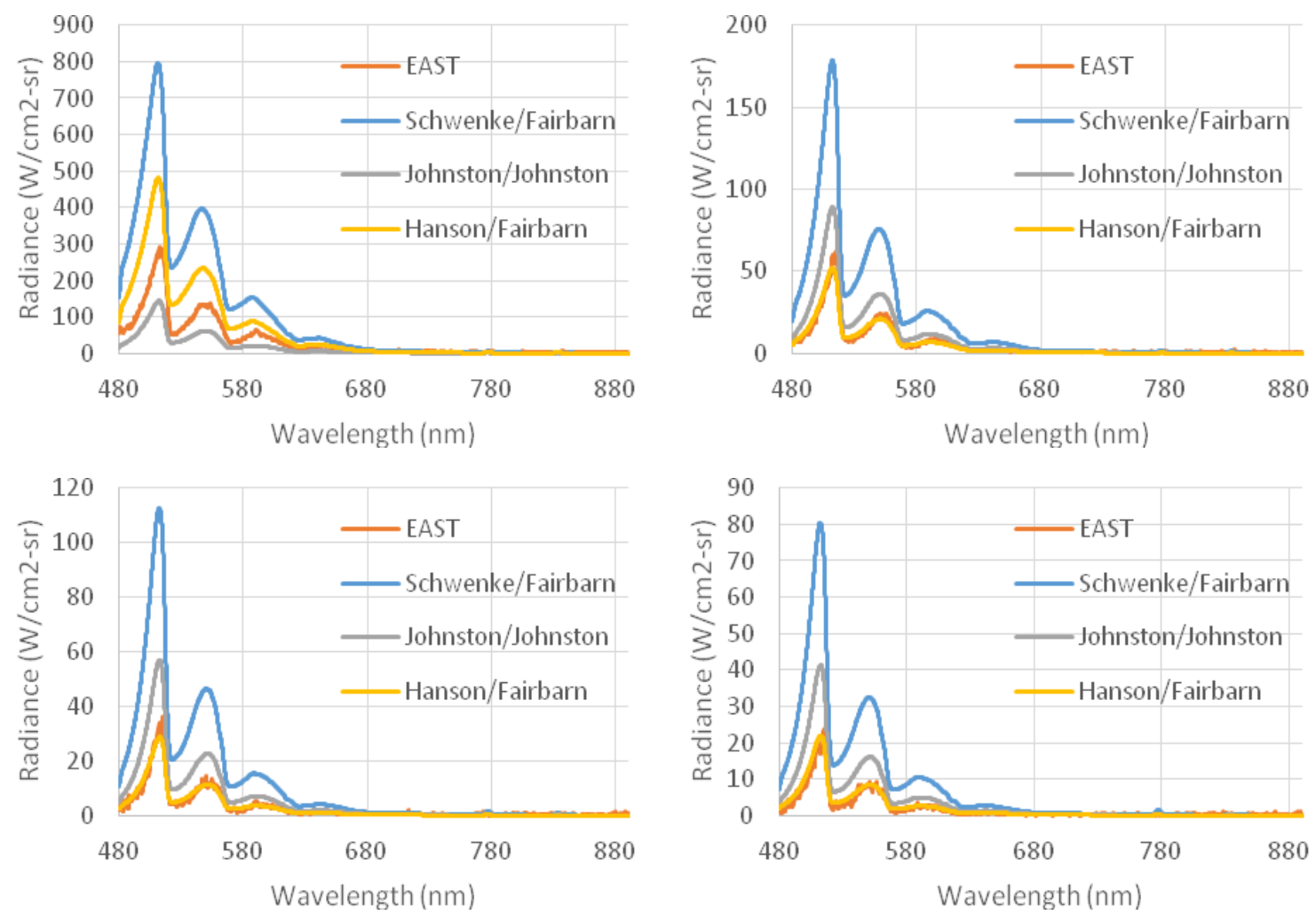

Figure 12. Comparison of spectral radiance at different positions behind the shock for the case of $5.65 \mathrm{~km} / \mathrm{s}$, 0.25 Torr. Positions correspond to (left-to-right, top-to-bottom) $0,2,4$ and $6 \mathrm{~cm}$ after the location of peak radiance.

Figure 12 shows the comparison of $\mathrm{C}_{2}$ spectral radiance at four different positions from the shock against kinetic models for $\mathrm{CO}$ dissociation based upon rates of Hanson, Johnston or Schwenke combined with the $\mathrm{C}_{2}$ dissociation/exchange rates of Johnston or Fairbarn. The combination of Hanson and Fairbarn rates show excellent agreement with observed $\mathrm{C}_{2}$ radiance at all points except the peak, where a non-Boltzmann model is likely required. This good agreement supports the use of Hanson's and Fairbarn's rates for CO chemistries. The applicability of these rates is further examined by comparing emission spectra over the range of velocities from $4.4-9.5 \mathrm{~km} / \mathrm{s}$ in Figure 13. From 4.4-6.6 km/s, the combination of Hanson and Fairbarn rates predicts the decay in $\mathrm{C}_{2}$ radiance well with some overprediction at the peak that is tentatively attributed to the Boltzmann model. The Johnston model overpredicts the decay at 4.4 and $5.7 \mathrm{~km} / \mathrm{s}$, but agrees well at higher velocity. The Johnston rates match both the peak radiance and shape of the curve well at $7.5 \mathrm{~km} / \mathrm{s}$ and above. The Hanson/Fairbarn rates more signficantly overpredict the non-equilibrium radiance in this velocity range. This overprediction bears some similarity to the overshoot in the infrared, suggesting too large a temperature is predicted early in the shock. As mentioned, the inclusion of electron impact dissociation, of both $\mathrm{CO}$ and $\mathrm{C}_{2}$, may serve to reduce this overshoot. 

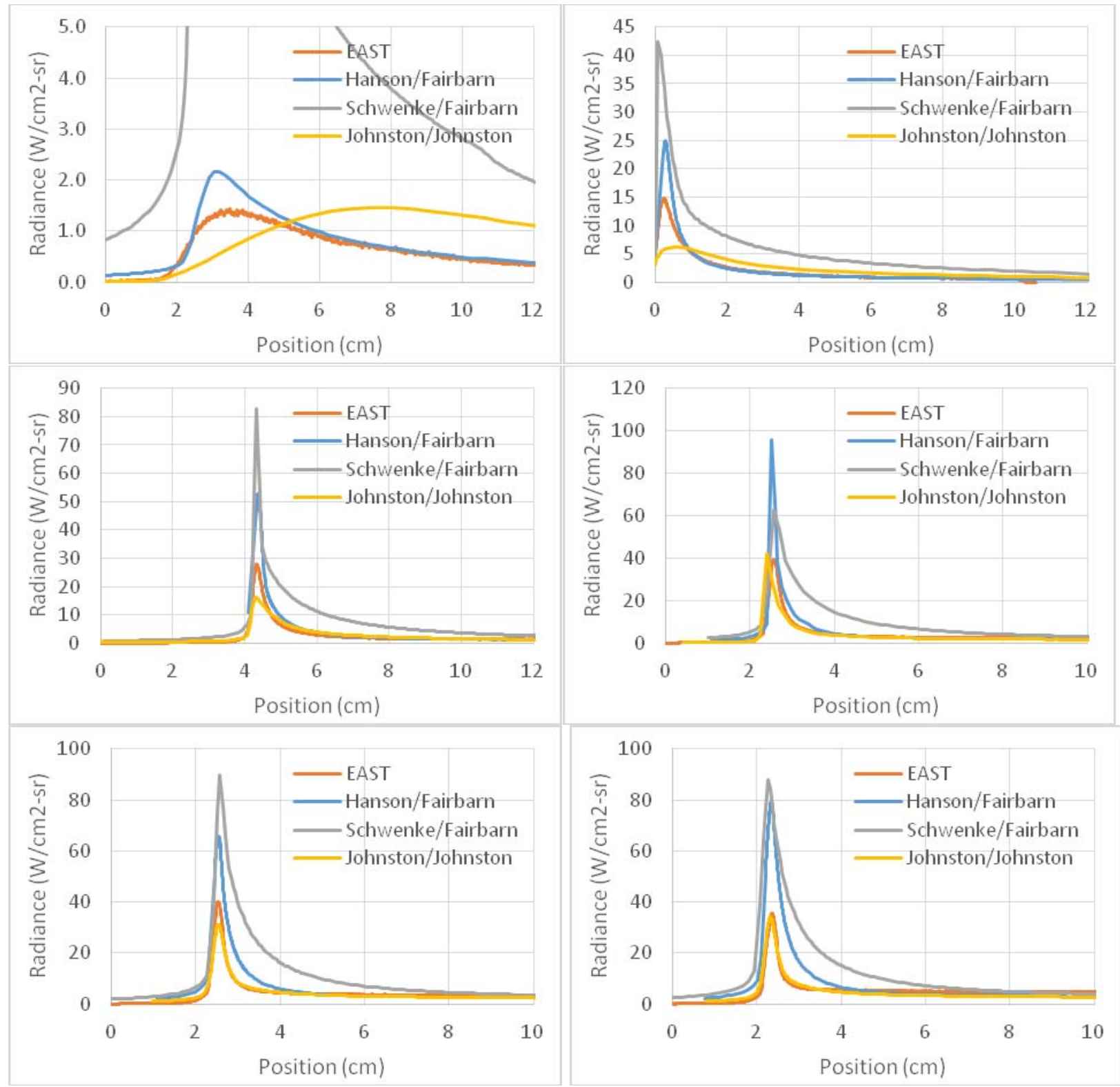

Figure 13. Comparison of radiance from $480-900 \mathrm{~nm}$. Velocities correspond to (left to right, top to bottom) $4.4 \mathrm{~km} / \mathrm{s}, 5.7 \mathrm{~km} / \mathrm{s}, 6.6 \mathrm{~km} / \mathrm{s}, 7.5 \mathrm{~km} / \mathrm{s}, 8.6 \mathrm{~km} / \mathrm{s}$ and $9.5 \mathrm{~km} / \mathrm{s}$.

\section{F. CO Vacuum Ultraviolet Radiation}

The most significant radiation source for high speed Mars entry is vacuum ultraviolet radiation from the $\mathrm{CO} 4^{\text {th }}$ Positive band. The $\mathrm{CO} 4^{\text {th }}$ Positive band has been examined in some detail in analyses of previous EAST data collected in $\mathrm{CO}_{2}[1,9]$. The comparison of $\mathrm{CO} 4^{\text {th }}$ positive radiation, from $145-190 \mathrm{~nm}$, over 6 velocities is shown in Figure 14. The Hanson rates predict the magnitude of VUV radiance well at velocities from $4.4-6.6 \mathrm{~km} / \mathrm{s}$, capturing both the peak and decay profiles. At velocities of $7.5 \mathrm{~km} / \mathrm{s}$ and above, the prediction is not as good, with peak radiances differing by as much as $2 \mathrm{x}$. The decay rates are also not matched above $8.6 \mathrm{~km} / \mathrm{s}$. The Johnston rates, on the other hand, do not match the radiance magnitudes at velocities of 4.4-5.7 km/s but agree well with peak values and profiles from $6.6 \mathrm{~km} / \mathrm{s}$ and above. 

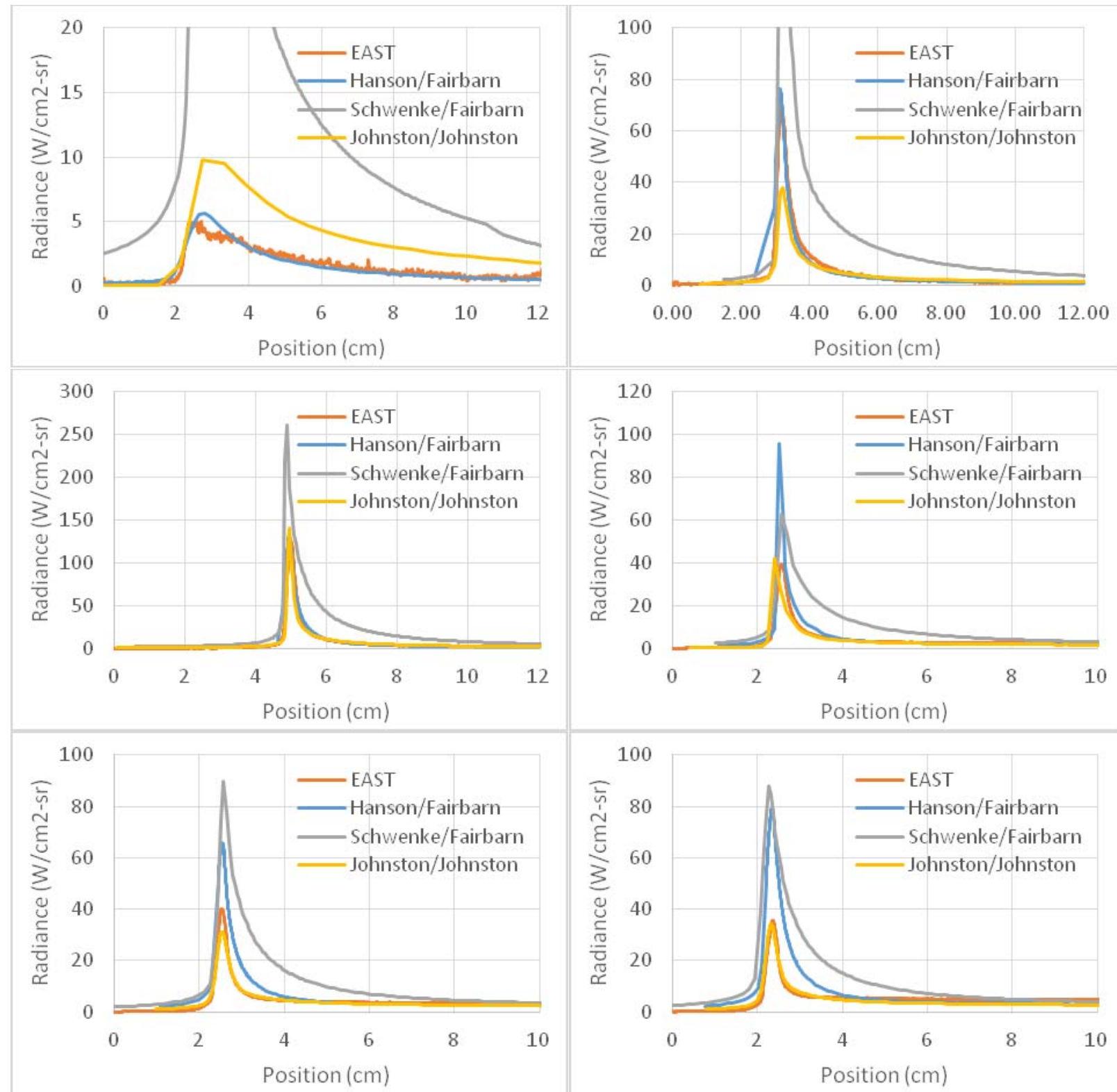

Figure 14. Comparisons of radiance measurements and predictions in the vacuum ultraviolet (145-190 $\mathrm{nm})$. Conditions correspond to velocities of $4.4 \mathrm{~km} / \mathrm{s}, 5.7 \mathrm{~km} / \mathrm{s}, 6.6 \mathrm{~km} / \mathrm{s}, 7.5 \mathrm{~km} / \mathrm{s}, 8.6 \mathrm{~km} / \mathrm{s}$ and $9.5 \mathrm{~km} / \mathrm{s}$.

To some extent, the agreement (or lack thereof) in Figure 14 may be fortuitous (or not). This is evident when spectral comparisons are examined. The spectral comparison of $\mathrm{CO} 4^{\text {th }}$ Positive radiation for the $5.65 \mathrm{~km} / \mathrm{s}$ case at peak radiation and $2 \mathrm{~cm}$ after peak radiation are shown in Fig. 15. At $2 \mathrm{~cm}$ behind the peak, the signal to noise ratio of the measurement has already become fairly low. It is apparent at the peak position that the agreement of the integrated signal is due to a combination of overpredicted radiance at low wavelength and an underprediction at higher wavelength. This is observed to a less significant degree at further distances from the shock front (Figure 15(b)). As an alternative approach, it has been attempted to fit the spectra by adjusting temperatures and CO number densities. This has yielded the results shown in Figure 15(c) and (d). Attempts to fit the data using a twotemperature model $\left(\mathrm{T}_{\mathrm{e}}=\mathrm{T}_{\mathrm{v}}, \mathrm{T}_{\mathrm{r}}=\mathrm{T}_{\mathrm{t}}\right)$ cannot correctly reproduce the results. A three-temperature model $\left(\mathrm{T}_{\mathrm{e}}, \mathrm{T}_{\mathrm{v}}, \mathrm{T}_{\mathrm{r}}=\mathrm{T}_{\mathrm{t}}\right)$ on the other hand reproduces the spectrum reasonably well. For the purposes of the $\mathrm{CO} 4^{\text {th }}$ Positive spectrum, the electron(ic) temperature $T_{e}$ is effectively used to determine the concentration of the A state of CO. If the spectrum is simulated as Boltzmann, $\mathrm{T}_{\mathrm{e}}$ would represent the electronic temperature and is used to determine the A state population based on a Boltzmann distribution. If the spectrum is simulated as non-Boltzmann, $\mathrm{T}_{\mathrm{e}}$ is the electron temperature, and is used to determine electron impact rates in the QSS equations. The three temperature fit requires 
$\mathrm{T}_{\mathrm{e}}=8200 \mathrm{~K}, \mathrm{~T}_{\mathrm{v}}=4300 \mathrm{~K}$ and $\mathrm{T}_{\mathrm{r}} / \mathrm{T}_{\mathrm{t}}=8300 \mathrm{~K}$. The $\mathrm{CO}$ density required is $1.2 \times 10^{17} \mathrm{~cm}^{-3}$. This combination of densities and temperatures are not in the space of valid solutions. For comparison, the CFD prediction near the peak (with Hanson's dissociation rate) has $\mathrm{T}_{\mathrm{v}}=\mathrm{T}_{\mathrm{e}}=9500 \mathrm{~K}, \mathrm{~T}_{\mathrm{r}}=\mathrm{T}_{\mathrm{t}}=9400 \mathrm{~K}$ and $\mathrm{n}_{\mathrm{CO}}=7.2 \times 10^{16} \mathrm{~cm}^{-3}$. Other factors contributing to this combination of parameters include the effect of spatial resolution on the experimental measurement, which effectively blends together spectra collected at multiple temperatures $[5,8]$, and the choice of $\mathrm{CO} 4^{\text {th }}$ Positive spectroscopic database[9], which could affect both the relative and absolute levels of transitions within the band system. At $2 \mathrm{~cm}$ from the peak radiance, fits of the spectra with one, two or three temperature models show some differences but are all within the noise of the measurement.
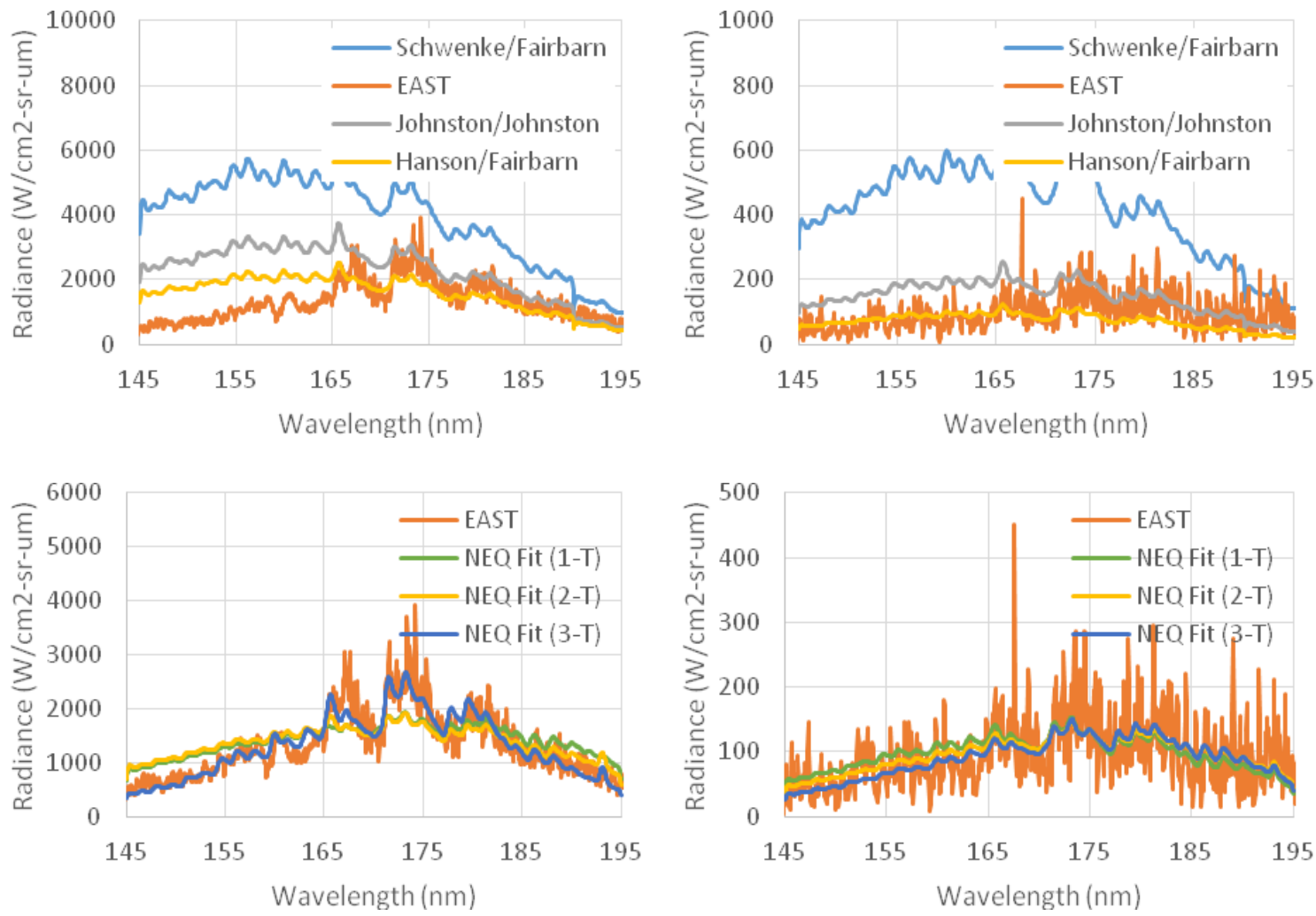

Figure 15. VUV spectra obtained at $5.65 \mathrm{~km} / \mathrm{s}$ at positions of (left) peak radiance and (right) $2 \mathrm{~cm}$ after peak radiance. Top images show comparison to spectra predicted with different kinetic models and bottom shows fits to the spectrum using one, two and three temperature models.

\section{Recommendations}

The combination of the observations in this work has produced some consistent trends. In particular, $\mathrm{CO}$ and $\mathrm{C}_{2}$ reaction rates proposed by Hanson and Fairbarn reproduce the data well at velocities up to $6.6 \mathrm{~km} / \mathrm{s}$. At higher velocities, the Johnston and Brandis model parameters appear to perform better. It remains to be determined whether the deviation of Hanson's rate from the data at higher velocity suggests the need for a merged Hanson/Johnston CO dissociation rate or whether a better modeling of electron impact parameters could rectify the high temperature discrepancies. Therefore, at this time, we reproduce in Table I the rate models for CO reactivity with different applicability in low velocity or high velocity regimes, using the modified Arrhenius form:

$$
\mathrm{k}=\mathrm{A} \mathrm{T}^{\mathrm{n}} \exp \left(-\mathrm{E}_{\mathrm{a}} / \mathrm{T}\right)
$$

Only the first three reactions were examined in this work, the rest are included from previous works $[1,6,19]$ for completeness. 
Table I. Recommended rate parameters based on this work, in modified Arrhenius form

\begin{tabular}{|c|c|c|c|c|c|c|c|c|}
\hline \multirow{2}{*}{ Reaction } & \multicolumn{4}{|c|}{ Up to $6.6 \mathrm{~km} / \mathrm{s}$} & \multicolumn{4}{|c|}{ Above $6.6 \mathrm{~km} / \mathrm{s}$} \\
\hline & $\mathrm{A}\left(\mathrm{cm}^{3} / \mathrm{mol} \cdot \mathrm{s}\right)$ & $\mathrm{n}$ & $E_{a}(K)$ & Ref & $\mathrm{A}\left(\mathrm{cm}^{3} / \mathrm{mol} \cdot \mathrm{s}\right)$ & $\mathrm{n}$ & $E_{a}(K)$ & Ref \\
\hline $\mathrm{CO}+\mathrm{M} \rightarrow \mathrm{C}+\mathrm{O}+\mathrm{M}$ & $7.99 \times 10^{38}$ & -5.5 & 129,060 & [21] & $1.20 \times 10^{21(\mathrm{a})}$ & -1.0 & 129,000 & [1] \\
\hline $\mathrm{C}_{2}+\mathrm{O} \rightarrow \mathrm{CO}+\mathrm{C}$ & $3.61 \times 10^{14}$ & 0 & 0 & [24] & & & & \\
\hline $\mathrm{CO}+\mathrm{C} \rightarrow \mathrm{C}_{2}+\mathrm{O}$ & & & & & $2.40 \times 10^{17}$ & -1.0 & 58,000 & {$[19]$} \\
\hline $\mathrm{C}_{2}+\mathrm{M} \rightarrow \mathrm{C}+\mathrm{C}+\mathrm{M}$ & $1.82 \times 10^{15}$ & 0 & 64,000 & [24] & $4.50 \times 10^{18}$ & -1.0 & 71,500 & [1] \\
\hline $\mathrm{CO}+\mathrm{O} \rightarrow \mathrm{C}+\mathrm{O}_{2}$ & $3.9 \times 10^{13}$ & -0.18 & 69,200 & [19] & $3.9 \times 10^{13}$ & -0.18 & 69,200 & [19] \\
\hline $\mathrm{O}_{2}+\mathrm{M} \rightarrow \mathrm{O}+\mathrm{O}+\mathrm{M}$ & $1.2 \times 10^{14}$ & 0 & 54,246 & [44] & $2.0 \times 10^{21(b)}$ & -1.5 & 59,360 & [19] \\
\hline $\mathrm{CO}_{2}+\mathrm{M} \rightarrow \mathrm{CO}+\mathrm{O}+\mathrm{M}$ & $7.47 \times 10^{12}$ & 0.5 & 52,321 & [45] & $6.90 \times 10^{21(\mathrm{c})}$ & -1.5 & 63,280 & [19] \\
\hline $\mathrm{CO}_{2}+\mathrm{O} \rightarrow \mathrm{CO}+\mathrm{O}_{2}$ & $2.71 \times 10^{14}$ & 0 & 33,800 & [46] & $2.71 \times 10^{14}$ & 0 & 33,800 & [46] \\
\hline $\mathrm{C}+\mathrm{e}^{-} \rightarrow \mathrm{C}^{+}+\mathrm{e}^{-}+\mathrm{e}^{-}$ & $3.7 \times 10^{31}$ & -3.0 & 130,700 & [19] & $3.7 \times 10^{31}$ & -3.0 & 130,700 & [19] \\
\hline $\mathrm{O}+\mathrm{e}^{-} \rightarrow \mathrm{O}^{+}+\mathrm{e}^{-}+\mathrm{e}^{-}$ & $3.9 \times 10^{33}$ & -3.78 & 158,500 & [47] & $3.9 \times 10^{33}$ & -3.78 & 158,500 & [47] \\
\hline $\mathrm{CO}+\mathrm{e}^{-} \rightarrow \mathrm{CO}^{+}+\mathrm{e}^{-}+\mathrm{e}^{-}$ & $4.5 \times 10^{14}$ & 0.275 & 163,500 & [48] & $4.5 \times 10^{14}$ & 0.275 & 163,500 & [48] \\
\hline $\mathrm{O}_{2}+\mathrm{e}^{-} \rightarrow \mathrm{O}_{2}^{+}+\mathrm{e}^{-}+\mathrm{e}^{-}$ & $2.19 \times 10^{10}$ & 1.16 & 130,000 & [48] & $2.19 \times 10^{10}$ & 1.16 & 130,000 & [48] \\
\hline $\mathrm{C}+\mathrm{O} \rightarrow \mathrm{CO}^{+}+\mathrm{e}^{-}$ & $8.8 \times 10^{8}$ & 1.0 & 33,100 & [19] & $8.8 \times 10^{8}$ & 1.0 & 33,100 & [19] \\
\hline $\mathrm{CO}+\mathrm{C}^{+} \rightarrow \mathrm{CO}^{+}+\mathrm{C}$ & $1.1 \times 10^{13}$ & 0 & 31,400 & [19] & $1.1 \times 10^{13}$ & 0 & 31,400 & [19] \\
\hline $\mathrm{O}+\mathrm{O} \rightarrow \mathrm{O}_{2}^{+}+\mathrm{e}^{-}$ & $7.1 \times 10^{2}$ & 2.7 & 80,600 & [49] & $7.1 \times 10^{2}$ & 2.7 & 80,600 & [49] \\
\hline $\mathrm{O}_{2}+\mathrm{C}^{+} \rightarrow \mathrm{O}_{2}^{+}+\mathrm{C}$ & $1.0 \times 10^{13}$ & 0 & 9,400 & [19] & $1.0 \times 10^{13}$ & 0 & 9,400 & [19] \\
\hline $\mathrm{O}_{2}^{+}+\mathrm{O} \rightarrow \mathrm{O}_{2}+\mathrm{O}^{+}$ & $2.19 \times 10^{10}$ & 1.16 & 130,000 & [49] & $2.19 \times 10^{10}$ & 1.16 & 130,000 & [49] \\
\hline
\end{tabular}

${ }^{(a)}$ Rate is increased by $1.5 \times$ when the collision partner is an atom

(b) Rate is increased by $5 \times$ when the collision partner is an atom

${ }^{(c)}$ Rate is increased by $2 \times$ the collision partner is an atom

\section{Conclusions}

This work has presented an analysis of $\mathrm{CO}$ radiation and diode laser absorption measured in a shock tube facility for a freestream pressure of $33 \mathrm{~Pa}$ and velocities ranging from 3-9 km/s. The intent of this work is to help build a robust kinetic and radiation model for use in probe entries to Mars and Venus, where CO is an important by-product in the shock layer. The combination of emission and absorption data have been used to extract temperature profiles behind the shock front. Translational temperature is obtained by Doppler broadening measurement, rotational and vibrational temperature are obtained through fits of the $\mathrm{C}_{2}$ Swan band and electronic temperature is obtained from Planck limited radiation in the vacuum ultraviolet. The four temperatures show relatively consistent decay profiles. The rate of decay is converted into a rate of consumption of $\mathrm{CO}$ using $1 \mathrm{D}$ shock conservation equations. The rates are found to be consistent with those of Hanson [21] and it is proposed this a compound reaction proceeding through metastable level(s) of CO. The newer quantum mechanical rate of Schwenke, et al.[23], which is only based upon the ground state of $\mathrm{CO}$, underpredicts the dissociation rate. Using Hanson's rate as a global constant is found to reproduce well the temperature relaxation rate at velocities up to $7.5 \mathrm{~km} / \mathrm{s}$. At higher velocity, the rate comparison is favorable though some deviation may be present at short time scales. The rate of Johnston and Brandis[1], which is the current standard for Mars entries, agrees with the temperature profile above $6.6 \mathrm{~km} / \mathrm{s}$.

Spectral data from the shock tube experiment was examined in terms of $\mathrm{CO}$ infrared radiation (fundamental vibrational transition), the $\mathrm{C}_{2}$ Swan band in the visible and the $\mathrm{CO} 4^{\text {th }}$ Positive band in the vacuum ultraviolet. The intensity of the infrared band is underpredicted by about $30 \%$ at most conditions. An overprediction of about $25 \%$ in laser absorption is observed at the same time. These simultaneous observations are not reconcilable through errors in the radiation input parameters. The underprediction shows no particular dependence on wavelength, making it unlikely to be reconciled through a non-Boltzmann distribution. A similar underprediction error has been reported for $\mathrm{CO}$ at $1200-2500 \mathrm{~K}$ and $0.5-3 \mathrm{~atm}$ in the literature.[40] It is suggested there may be additional unaccounted states in the model, which also impacts the absorption calculation through the CO partition function. The trend of CO radiation with position is fairly flat. The flat trend is predicted by Hanson's rate [21] up to $6.6 \mathrm{~km} / \mathrm{s}$ or Johnston's rate [1] up to $8.6 \mathrm{~km} / \mathrm{s}$. At higher velocities, a radiation overshoot is predicted that is not observed in the experiment. 
The $\mathrm{C}_{2}$ Swan band is used to examine the rates for $\mathrm{C}_{2}$ formation through exchange reactions of $\mathrm{C}$ with $\mathrm{CO}$ and dissociation through heavy particle impact. Rates proposed by Park [19] and adopted (with some modification) by Johnston [1] are compared to rates measured by Fairbarn [24, 42] and adopted (with some modification) by Fujita[20]. Fairbarn's rates, in combination with Hanson's dissociation rate, are shown to more accurately predict $\mathrm{C}_{2}$ radiation at velocities up to $6.6 \mathrm{~km} / \mathrm{s}$. Some overprediction of the radiation peak is always observed and attributed to the absence of a non-Boltzmann model. The rates of Johnston show good agreement with the data at $7.5 \mathrm{~km} / \mathrm{s}$ and above, although all comparisons are made with a Boltzmann model which may lead to a false agreement.

The CO VUV radiation is not matched well spectrally at peak radiance. The data may be fit with a 3temperature model where the electron(ic) temperature is very close to the rotational/translational temperature, and the vibrational temperature is much lower. This observation is tempered however by questions about the accuracy of the $\mathrm{CO} 4^{\text {th }}$ Positive spectral database and the effect of spatial resolution on the spectrum. At distances as short as a few centimeters from the peak, the multi-temperature fit is no longer required. In terms of predicting the trend of $\mathrm{CO} 4^{\text {th }}$ Positive radiation, Hanson's rates [21] match the data up to $6.6 \mathrm{~km} / \mathrm{s}$. Johnston's rates [1] match the data at $6.6 \mathrm{~km} / \mathrm{s}$ and above.

Areas for further investigation identified here include the following. First, electron impact dissociation of CO must be examined to determine if it impacts the modeling at higher velocity. If not, a rate coefficient that bridges that of Hanson and Johnston may be a required. Second, inconsistency in the prediction of CO line absorption, CO infrared radiation and $\mathrm{CO}$ vacuum ultraviolet radiation suggests the need for re-examination of the $\mathrm{CO}$ energy levels, dipole moments and partition functions. Third, resolution of the overprediction of $\mathrm{C}_{2}$ radiance at short time scales likely requires implementation of a non-Boltzmann model for $\mathrm{C}_{2}$.

The common observations across all measurements is one set of rate performing succesfully at the velocity regime up to $6.6 \mathrm{~km} / \mathrm{s}$ and a second set of rates for velocities above $6.6 \mathrm{~km} / \mathrm{s}$. While it is possible these rates could be reconciled to come up with one set of rates that matches at all velocities, this is not done at this time due to some remaining open questions. Two sets of rates are recommended for usage in different velocity regimes.

\section{Acknowledgments}

The authors would like to thank NASA's Entry Systems Modeling (ESM) project. A. M. Brandis and B.A. Cruden are supported through the NNA15BB15C contract to Analytical Mechanics Associates. M.E. MacDonald is supported through the NNA16BD26C contract to Jacobs Technology.

\section{References}

1. Johnston, C. O., and Brandis, A. M., "Modeling of nonequilibrium CO Fourth-Positive and CN Violet emission in CO2-N2 gases," Journal of Quantitative Spectroscopy and Radiative Transfer, Vol. 149, 2014, pp. 303-317.

2. Grinstead, J. H., Wright, M. J., Bogdanoff, D. W., and Allen, G. A., "Shock Radiation Measurements for Mars Aerocapture Radiative Heating Analysis," Journal of Thermophysics and Heat Transfer, Vol. 23, No. 2, 2009, pp. 249255.

3. Cruden, B. A., Prabhu, D., and Martinez, R., "Absolute Radiation Measurement in Venus and Mars Entry Conditions," Journal of Spacecraft and Rockets, Vol. 49, No. 6, 2012, pp. 1069-1079.

4. $\quad$ Cruden, B. A., "Radiance Measurement for Low Density Mars Entry," AIAA Paper 2012-2742.

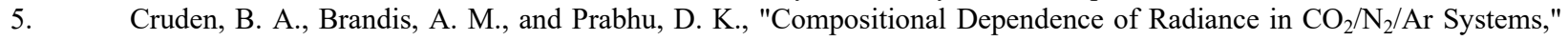
AIAA 2013-2502.

6. Cruden, B. A., Prabhu, D. K., and Brandis, A. M., "Measurement and Characterization of Mid-wave Infrared Radiation in $\mathrm{CO}_{2}$ Shocks," AIAA Paper 2014-2962.

7. Cruden, B. A., Brandis, A. M., White, T. R., Mahzari, M., and Bose, D., "Radiative Heating During Mars Science Laboratory Entry: Simulation, Ground Test, and Flight," Journal of Thermophysics and Heat Transfer, Vol. 30, No. 3, 2016, pp. 642-650.

8. Brandis, A. M., Johnston, C. O., Cruden, B. A., and Prabhu, D. K., "Investigation of Nonequilibrium Radiation for Mars Entry," AIAA Paper 2013-1055.

9. Brandis, A. M., Johnston, C. O., Cruden, B. A., Prabhu, D. K., Wray, A. A., Liu, Y., Schwenke, D. W., and Bose, D., "Validation of CO 4th positive radiation for Mars entry," Journal of Quantitative Spectroscopy and Radiative Transfer, Vol. 121, 2013, pp. 91-104.

10. Johnston, C., Brandis, A., Panesi, M., and Sutton, K., "Shock Layer Radiation Modeling and Uncertainty for Mars Entry," AIAA Paper 2012-2866, 2012

11. Takayanagi, H., and Fujita, K., "Absolute Radiation Measurements Behind Strong Shock Wave In Carbon Dioxide Flow for Mars Aerocapture Missions," AIAA Paper 2012-2744. 
12. Takayanagi, H., and Fujita, K., "Infrared Radiation Measurement behind Shock Wave in Mars Simulant Gas for Aerocapture Missions," AIAA Paper 2013-2504.

13. Potter, D., Eichmann, T., Brandis, A., Morgan, R., Jacobs, P., and McIntyre, T., "Simulation of radiating $\mathrm{CO}_{2}-\mathrm{N}_{2}$ shock layer experiments at hyperbolic entry conditions," 2008.

14. MacDonald, M., and Cruden, B. A., "A Tunable Laser Absorption Diagnostic for Measurements of CO in ShockHeated Gases," AIAA Paper 2016-3694.

15. MacDonald, M. E., Brandis, A. M., and Cruden, B. A., "Post-Shock Temperature and CO Number Density Measurements in CO and CO2," AIAA Paper 2017-4342.

16. MacDonald, M. E., and Cruden, B. A., "Temperature and CO Number Density Measurements in Shocked $\mathrm{CO}^{2}$ and $\mathrm{CO}_{2}$ via Tunable Diode Laser Absorption Spectroscopy," AIAA Paper (to be presented).

17. Cruden, B. A., "Absolute Radiation Measurements in Earth and Mars Entry Conditions," RTO-EN-AVT-218, 2014.

18. McBride, B. J., and Gordon, S., "Computer program for calculation of complex chemical equilibrium compositions and applications II. User's Manual and Program Description," NASA RP-1311-P2, June 1996.

19. Park, C., Howe, J. T., Jaffe, R. L., and Candler, G. V., "Review of chemical-kinetic problems of future NASA missions, II: Mars entries," Journal of Thermophysics and Heat Transfer, Vol. 8, 1994, pp. 9-22.

20. Fujita, K., Yamada, T., and Ishii, N., "Impact of Ablation Gas Kinetics on Hyperbolic Entry Radiative Heating," 2006.

21. Hanson, R. K., "Shock-tube study of carbon monoxide dissociation kinetics," The Journal of Chemical Physics, Vol. 60, No. 12, 1974, p. 4970.

22. Appleton, J. P., "Shock-Tube Study of Carbon Monoxide Dissociation Using Vacuum-Ultraviolet Absorption," The Journal of Chemical Physics, Vol. 52, No. 5, 1970, p. 2205.

23. Schwenke, D. W., Jaffe, R. L., and Chaban, G. M., "Collisional Dissociation of CO: ab initio Potential Energy Surfaces and Quasiclassical Trajectory Rate Coefficients," Journal of Physical Chemistry, submitted. Fairbairn, A. R., "The dissociation of carbon monoxide," Proc. R. Soc. London A, Vol. 312, 1969, pp. 207-227.

25. Adamovich, I., Lempert, W., Utkin, Y., and Rich, J., "Thermal Mode Nonequilibrium in High Speed Gas Dynamics," AIAA Paper 2006-584.

26. Jaffe, R. L., Schwenke, D. W., Chaban, G. M., Prabhu, D. K., Johnston, C. O., and Panesi, M., "On the development of a new nonequilibrium chemistry model for Mars entry," AIAA Paper 2017-1372.

27. Venturi, S., and Panesi, M., "Investigating CO Dissociation by means of Coarse Grained Ab-Initio Rate Constants," AIAA Paper 2018-1232.

28. Park, C., "Rate Parameters for Electronic Excitation of Diatomic Molecules II. Heavy Particle-Impact Processes," AIAA Paper 2008-1446.

29. Grover, M. S., Singh, N., Schwartzentruber, T. E., and Jaffe, R. L., "Dissociation and internal excitation of molecular nitrogen due to N2-N collisions using direct molecular simulation," 2017.

30. Jaffe, R. L., Schwenke, D. W., Grover, M., Valentini, P., Schwartzentruber, T. E., Venturi, S., and Panesi, M., "Comparison of quantum mechanical and empirical potential energy surfaces and computed rate coefficients for N2 dissociation," AIAA Paper 2016-0503.

31. Brandis, A. M., Johnston, C. O., and Cruden , B. A., "Investigation of Non-equilibrium Radiation for Earth Entry," AIAA Paper 2016-3690, Jun. 2016.

32. Hure, J. M., and Roueff, E., "Analytic representations of rovibrational dipole matrix elements for the CO molecule and its isotopomers," Astronomy and Astrophysics Supplement Series, Vol. 117, No. 3, 1996, pp. 561-568.

33. Goorvitch, D., "Infrared CO Line List for the X ${ }^{1} \Sigma^{+}$State," Astrophys J Suppl Series, Vol. 95, 1994, pp. $535-552$.

34. Goorvitch, D., and C. Chackerian, J., "Calculation of ${ }^{12} \mathrm{C}^{16} 0$ and ${ }^{13} \mathrm{C}^{16} 0 \mathrm{X}^{1} \Sigma^{+}$Rovibrational Intensities for $\mathrm{v}<20$ and $\mathrm{J}$ $<150$," Astrophys J Suppl Series, Vol. 91, 1994, pp. 483-489.

35. Langhoff, S. R., and Bauschlicher, C. W., "Global dipole moment function for the X $1 \Sigma+$ ground state of CO," The Journal of Chemical Physics, Vol. 102, No. 13, 1995, pp. 5220-5225.

36. Li, G., Gordon, I. E., Rothman, L. S., Tan, Y., Hu, S.-M., Kassi, S., Campargue, A., and Medvedev, E. S., "Rovibrational Line Lists for Nine Isotopologues of the Co Molecule in Thex $1 \Sigma+$ Ground Electronic State," The Astrophysical Journal Supplement Series, Vol. 216, No. 1, 2015, p. 15.

37. Chandra, S., Maheshwari, V. U., and Sharma, A. K., "Einstein A-coefficients for vib-rotational transitions in CO," Astronomy and Astrophysics Supplement Series, Vol. 117, No. 3, 1996, pp. 557-559.

38. Tashkun, S. A., Velichko, T. I., and Mikhailenko, S. N., "Critical evaluation of measured pure-rotation and rotationvibration line positions and an experimental dataset of energy levels of ${ }^{12} \mathrm{C}^{16} \mathrm{O}$ in $\mathrm{X}^{1} \Sigma^{+}$state," Journal of Quantitative Spectroscopy and Radiative Transfer, Vol. 111, No. 9, 2010, pp. 1106-1116.

39. McGuire, S. D., Tibère-Inglesse, A. C., and Laux, C. O., "Infrared spectroscopic measurements of carbon monoxide within a high temperature ablative boundary layer," Journal of Physics D: Applied Physics, Vol. 49, No. 48, 2016, p. 485502.

40. Alberti, M., Weber, R., and Mancini, M., "Absorption of infrared radiation by carbon monoxide at elevated temperatures and pressures: Part A. Advancing the line-by-line procedure based on HITEMP-2010," Journal of Quantitative Spectroscopy and Radiative Transfer, Vol. 200, 2017, pp. 258-271.

41. Beck, W. H., and Mackie, J. C., "Formation and dissociation of C2 from high temperature pyrolysis of acetylene," Journal of the Chemical Society, Faraday Transactions 1: Physical Chemistry in Condensed Phases, Vol. 71, 1975, pp. 1363-1371. 
42. Fairbairn, A. R., "Shock-tube study of the dissociation rate of CN," Journal of Chemical Physics, Vol. 51, 1969, pp. 972-975.

43. Kruse, T., and Roth, P., "Kinetics of C2 Reactions during High-Temperature Pyrolysis of Acetylene," J. Phys. Chem. A, Vol. 101, 1997, pp. 2138-2146.

44. Warnatz, J., "Rate coefficients in the C/H/O system," Combustion Chemistry, Springer-Verlag, New York, 1984, pp. 197-360.

45. Ebrahim, N. A., and Sandeman, R. J., "Interferometric studies of carbon dioxide dissociation in a free-piston shock tube," The Journal of Chemical Physics, Vol. 65, No. 9, 1976, p. 3446.

46. Ibragimova, L. B., "Recommended rate constants of CO + O2 - reversible - CO2 + O reactions," Khim. Fiz., Vol. 10, 1991, pp. 307-310.

47. Park, C., Nonequilibrium Hypersonic Aerothermodynamics, New York: John Wiley \& Sons, 1990.

48. Teulet, P., Gonzalez, J., Mercado-Cabrera, A., Cressault, Y., and Gleizes, A., "One-dimensional hydro-kinetic modelling of the decaying arc in air-PA66-copper mixtures: I. Chemical kinetics, thermodynamics, transport and radiative properties," Journal of Physics D: Applied Physics, Vol. 42, No. 17, 2009, p. 175201.

49. Park, C., "Review of chemical-kinetic problems of future NASA missions. I - Earth entries," Journal of Thermophysics and Heat Transfer, Vol. 7, No. 3, 1993, pp. 385-398. 